\title{
The Influence of Continental Ice Sheets on the Climate of an Ice Age
}

\author{
S. Manabe ANd A. J. Broccoli
}

Geophysical Fluid Dynamics Laboratory/NOAA, Princeton University, Princeton, New Jersey

\begin{abstract}
The climate influence of the land ice that existed 18,000 years before present (18K B.P.) is investigated by use of a general circulation model of the atmosphere coupled with a static mixed layer ocean. Simulated climates are obtained from two versions of the model: one with the land ice distribution of the present and the other with that of $18 \mathrm{~K}$ B.P. In the northern hemisphere the tropospheric flow field is strongly influenced by the Laurentide ice sheet and features a split flow straddling the ice sheet, with a strong jet stream forming the southern branch. The northern branch of the flow brings very cold air over the North Atlantic Ocean, where thick sea ice is maintained. The distribution of sea surface temperature (SST) difference between the two experiments in the northern hemisphere resembles the difference between the SST at 18K B.P. and at present, as estimated by the CLIMAP Project (1981). The 18K B.P. ice sheets have very little influence upon atmospheric temperature and SST in the southern hemisphere. This is because the interhemispheric heat transport hardly changes as the loss of heat energy due to the reflection of solar radiation by continental ice sheets in the northern hemisphere is almost completely counterbalanced by the in situ reduction of upward terrestrial radiation. Hydrologic changes in the model climate are also found, with statistically significant decreases in soil moisture occurring in a zone located to the south of the ice sheets in North America and Eurasia. These findings are consistent with some geological evidence of regionally drier climates from the last glacial maximum.
\end{abstract}

\section{INTRODUCTION}

The climate of an ice age has been the subject of many recent studies conducted by using mathematical models of climate. One can classify these studies into two categories. In the first category are studies aiming at the identification of physical mechanisms responsible for causing the transition between an interglacial and glacial climate. The second category includes studies exploring how the cold climate of an ice age is maintained under the influences of various physical factors. The present study belongs to the latter category. It is likely that the results from the studies of the second category will also provide valuable information for those of the first category.

It has been suggested that the temporal variation of the orbital parameters of the earth is responsible for causing ice age climates to develop [e.g., Milankovitch, 1941], and the spectral analysis of paleoclimatic data from deep sea cores supports the speculation [Hays et al., 1976]. However, by the time the last glacial period had reached its peak at 18,000 years before present (18K B.P.) the orbital parameters were very similar to those at the present. (This is due to the $\sim 20,000$-year period of the perihelion cycle and the present obliquity being near the average value in its 41,000 -year cycle, which recurs every 20,500 years.) Thus it is reasonable to assume that, while temporal variation of the orbital parameters may have induced the start of the last glaciation, differences in the orbital parameters were not responsible for maintaining the ice age climate of $18 \mathrm{~K}$ B.P. Other physical factors must have been responsible for maintaining the cold ice age climate.

One of the important factors helping to maintain a low atmospheric temperature during an ice age is the existence of extensive continental ice sheets that reflect a large fraction of insolation. The present study investigates the influences of continental ice sheets on the climate of the last major ice age by use of a mathematical model of climate constructed at the

Copyright 1985 by the American Geophysical Union.

Paper number 4D1227. 0148-0227/85/004D-1227\$05.00
Geophysical Fluid Dynamics Laboratory of NOAA. In particular it attempts to determine whether the influence of the continental ice sheets is large enough to account for the cold climate of an ice age or whether it is necessary to consider other factors.

This study is preceded by two important developments. The first is the detailed reconstruction of an ice age environment by the CLIMAP (Climate: Long-Range Investigation, Mapping, and Prediction) project. Based upon the results from the analysis of deep-sea cores and other geological data, they reconstructed the global distributions of sea surface temperature, surface albedo, and continental ice at the peak of the last major glaciation, i.e., at 18K B.P. [CLIMAP Project, 1981]. This reconstruction provided an ideal data base for the present study.

The second development is the construction of a mathematical model of the joint atmosphere-mixed layer ocean system. In order to study the distribution of the climate change resulting from a future increase of the atmospheric $\mathrm{CO}_{2}$, Manabe and Stouffer [1980] constructed a climate model that consists of a general circulation model of the atmosphere and a simple mixed-layer model of the oceans. This model successfully reproduces many of the features of the global climate and its seasonal variation, despite drastic simplifications adopted in the construction of the model.

By use of an atmosphere-mixed layer ocean model, in which sea surface temperature (SST) is a predicted quantity, we wish to evaluate the influence of various ice-age boundary conditions upon the SST distribution of the model. Thus this study is fundamentally different from those of Gates [1976a, b] and Manabe and Hahn [1977], in which CLIMAP SST's were used as fixed boundary conditions for simulating an ice age climate.

This is the first of a series of numerical experiments in which CLIMAP data is used to quantitatively assess the importance of various boundary conditions in maintaining an ice-age climate. In the present study the influence of continental ice will be examined. Future studies will consider the importance of other processes and boundary conditions. Preliminary results from the present study are found in Manabe and Broccoli $[1984 a, b]$. 


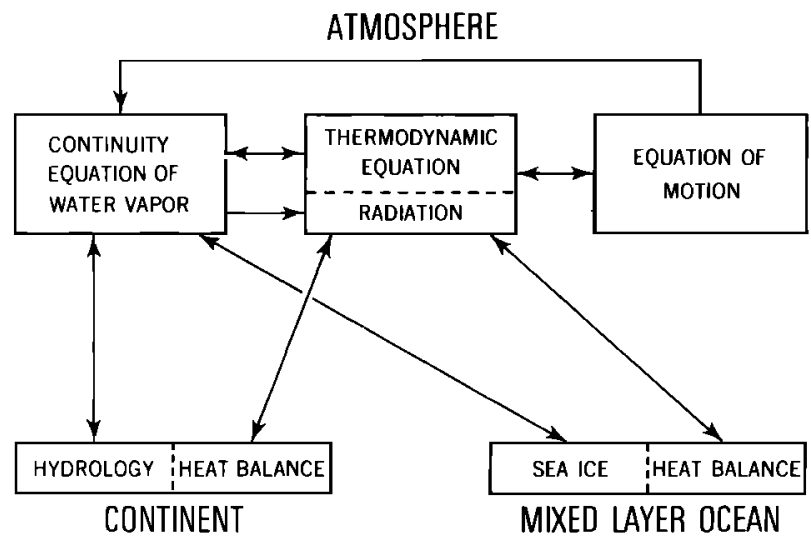

Fig. 1. Box diagram illustrating the basic structure of the coupled atmosphere/mixed-layer ocean climate model.

\section{Model Structure}

As the box diagram of Figure 1 indicates, the mathematical model used for this study consists of three basic units: (1) a general circulation model of the atmosphere, (2) a heat and water balance model over the continents, and (3) a simple model of the oceanic mixed layer. A description of these three units follows.

The atmospheric general circulation model computes the rates of change with time of the vertical component of vorticity, horizontal divergence, temperature, moisture, and surface pressure based on the equations of motion, the thermodynamical equation, and the continuity equations for moisture and mass. The prognostic equations assume the hydrostatic approximation and use a terrain-following vertical-coordinate system.

The horizontal distributions of the primary variables are represented by a finite number of spherical harmonics. The model predicts the rate of change of the spectral components by computing the tendencies from the prognostic equations at all grid points and transforming them to the spectral domain as suggested by Orszag [1970]. The horizontal resolution of the spectral representation of a field depends upon the degree of truncation of spherical harmonic components. The present model adopts the "rhomboidal 15" wave number truncation, in which 15 associated Legendre functions are retained for each of 15 Fourier components with the lowest zonal wave numbers. Vertical derivatives appearing in the prognostic equations are computed by a centered, second-order finite difference with nine unevenly spaced levels.

The numerical time integration of the prognostic equations is conducted by a semiimplicit method in which the linear and nonlinear components of the rate of change of a variable are separated and time integrated implicitly and explicitly, respectively. To prevent the growth of fictitious computational solutions, time smoothing is applied at each time step [Robert, 1966].

The dynamical component of the model described above was developed by Gordon and Stern [1974, 1982] and is very similar to spectral models developed by Bourke [1974] and Hoskins and Simmons [1975]. The performance of this spectral model of the atmospheric general circulation is described in detail by Manabe et al. [1979b] and Manabe and Hahn [1981].

The distribution of incoming solar radiation at the top of the atmosphere is prescribed. Computation of the flux of solar radiation is performed in a manner similar to that described by Lacis and Hansen [1974]. For simplicity the diurnal variation is removed. Terrestrial radiation is computed by the method developed by Rodgers and Walshaw [1966] and modified by Stone and Manabe [1968]. The depletion of solar radiation and the transfer of terrestrial radiation is computed by taking into consideration the effects of water vapor, carbon dioxide, ozone, and cloud cover. The distribution of water vapor is determined from the prognostic equation for water vapor. The mixing ratio of carbon dioxide is assumed to be constant everywhere. Ozone is specified as a function of latitude, height, and season.

Cloud cover is prescribed to be zonally uniform and invariant with respect to season. The assumption of fixed cloud cover is made because a reliable parameterization of the cloud-radiation feedback process is not available at the present time. Nevertheless, in view of the dominant influence of cloud cover upon the distributions of radiative fluxes in the atmosphere, it is possible that the climatic influence of continental ice sheets is significantly modified by cloud variation. This is the subject of future investigation by use of a climate model in which the cloud-radiation feedback process is taken into consideration.

Precipitation is predicted whenever supersaturation occurs in the model. If precipitation occurs while the air temperature just above the surface is below freezing, snowfall is forecast; otherwise any precipitation is assumed to fall as rain. A moist convection adjustment scheme is used to represent moist convection processes. Further details of the prognostic system of water vapor are found in Manabe et al. [1965].

Over the continents, surface temperatures are determined by the requirement that no heat be stored in the soil. The surface albedo, which is needed to determine the net solar flux at the ground, is prescribed geographically, based on a study by Posey and Clapp [1964]. However, these albedos are replaced by higher values wherever continental ice or snow cover are present. The albedo for continental ice is prescribed to be $70 \%$. The albedo for snow cover is a function of latitude and show depth. Table 1 gives the albedo values for deep snow as a function of latitude. When the water equivalent of the snow depth is below $1 \mathrm{~cm}$, it is assumed that the snow albedo decreases from the values in Table 1 to the albedo of the underlying surface as a square root lunction of snow depth. A change in snow depth is predicted as the net contribution from snowfall, sublimation, and snowmelt, with the latter two determined from the surface heat budget.

The groundwater budget is computed by the "bucket method." The soil is assumed to have a water-holding capacity of $15 \mathrm{~cm}$. If the computed soil moisture exceeds this amount, the excess is assumed to be runoff. Changes in soil moisture are computed from the rates of rainfall, evaporation, snowmelt, and runoff. Evaporation from the soil is determined as a function of soil moisture and the potential evaporation rate

TABLE 1. Albedo (\%) of Snow and Sea Ice as a Function of Latitude

\begin{tabular}{lccc}
\hline & \multicolumn{3}{c}{ Latitude, deg } \\
\cline { 2 - 4 } & $0-55$ & $55-66.5$ & $66.5-90$ \\
\hline Deep snow & 60 & $60 \sim 80^{*}$ & 80 \\
Thick sea ice & 50 & $50 \sim 70$ & 70 \\
Melting & 45 & 45 & 45 \\
\hline
\end{tabular}

$* \sim$ means linear interpolation with respect to latitude between the two values. 

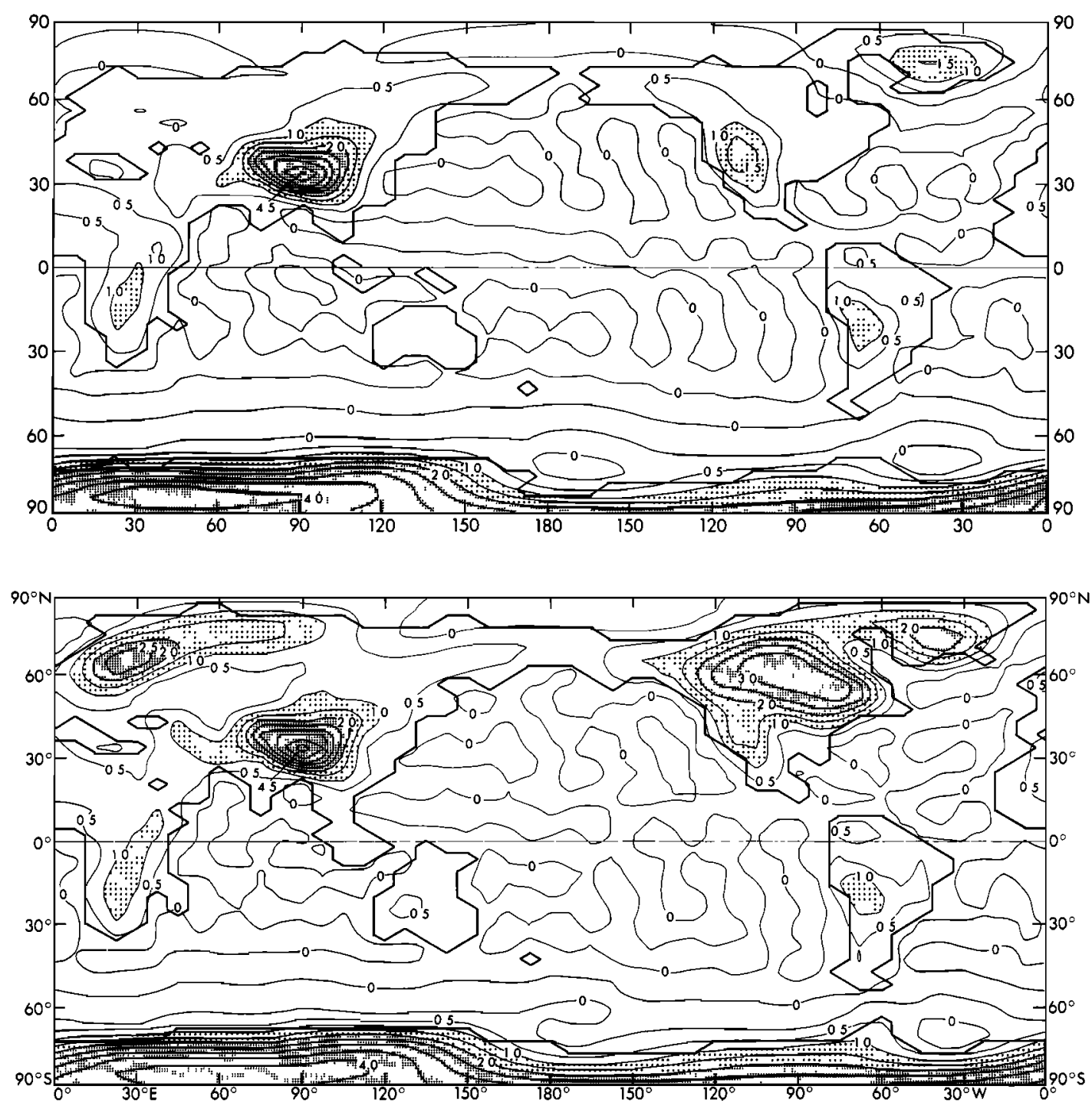

Fig. 2. Terrain height in kilometers above sea level as used by the model. As noted in the text, the topographic features are smoothed considerably as a result of spectral truncation: (top) present; (bottom) 18K B.P.

(i.e., the hypothetical evaporation rate from a completely wet soil). Further details of the hydrologic computations can be found in Manabe [1969].

The oceanic mixed-layer model consists of a vertically isothermal layer of water with a uniform depth of $68.5 \mathrm{~m}$. This thickness was chosen to yield approximately the observed seasonal amplitude of sea surface temperature (SST). This model takes into consideration the large heat capacity of the oceanic mixed layer but neglects the effects of horizontal heat transport by ocean currents and of the heat exchange between the mixed layer and the deeper parts of the ocean.

Over ice-free regions the rate of change of the mixed-layer temperature with time is computed from the net contribution of the solar and terrestrial radiation fluxes and the sensible and latent heat fluxes at the ocean surface. In the presence of sea ice the mixed-layer temperature is fixed at the freezing point of seawater $\left(-2^{\circ} \mathrm{C}\right)$, and the heat conduction through the ice is balanced by the latent heat of freezing (melting) at the bottom of the ice layer. This process together with melting at the ice surface, sublimation, and snowfall determines the change in ice thickness [Bryan, 1969]. For the computation of net solar radiation at the oceanic surface, albedo is prescribed as a function of latitude. Over regions covered by sea ice, higher surface albedo values are prescribed as a function of latitude and ice thickness. Table 1 gives the albedo values for thick sea ice as a function of latitude. The formation of meltwater puddles is parameterized by lowering the surface albedo to $45 \%$ when the surface temperature reaches the melting point. When the ice thickness is less than $0.5 \mathrm{~m}$, the albedo is further reduced from the values in Table 1 to the lower albedo of the underlying water surface as a square root function of ice thickness. A more detailed description of the mixed-layer ocean model can be found in Manabe and Stouffer [1980].

\section{NumERICAL EXPERIMENTS}

\section{3a. Experimental Design}

In order to evaluate the influence of continental ice sheets on the climate of an ice age, two long-term integrations of the atmosphere-mixed layer ocean model described in the preceding section are conducted. The first time integration, hereafter identified as the standard experiment, assumes (as a boundary condition) the modern distribution of continental ice, as reflected by the topography shown in the upper portion of Figure 2. The second time integration assumes the distribution 


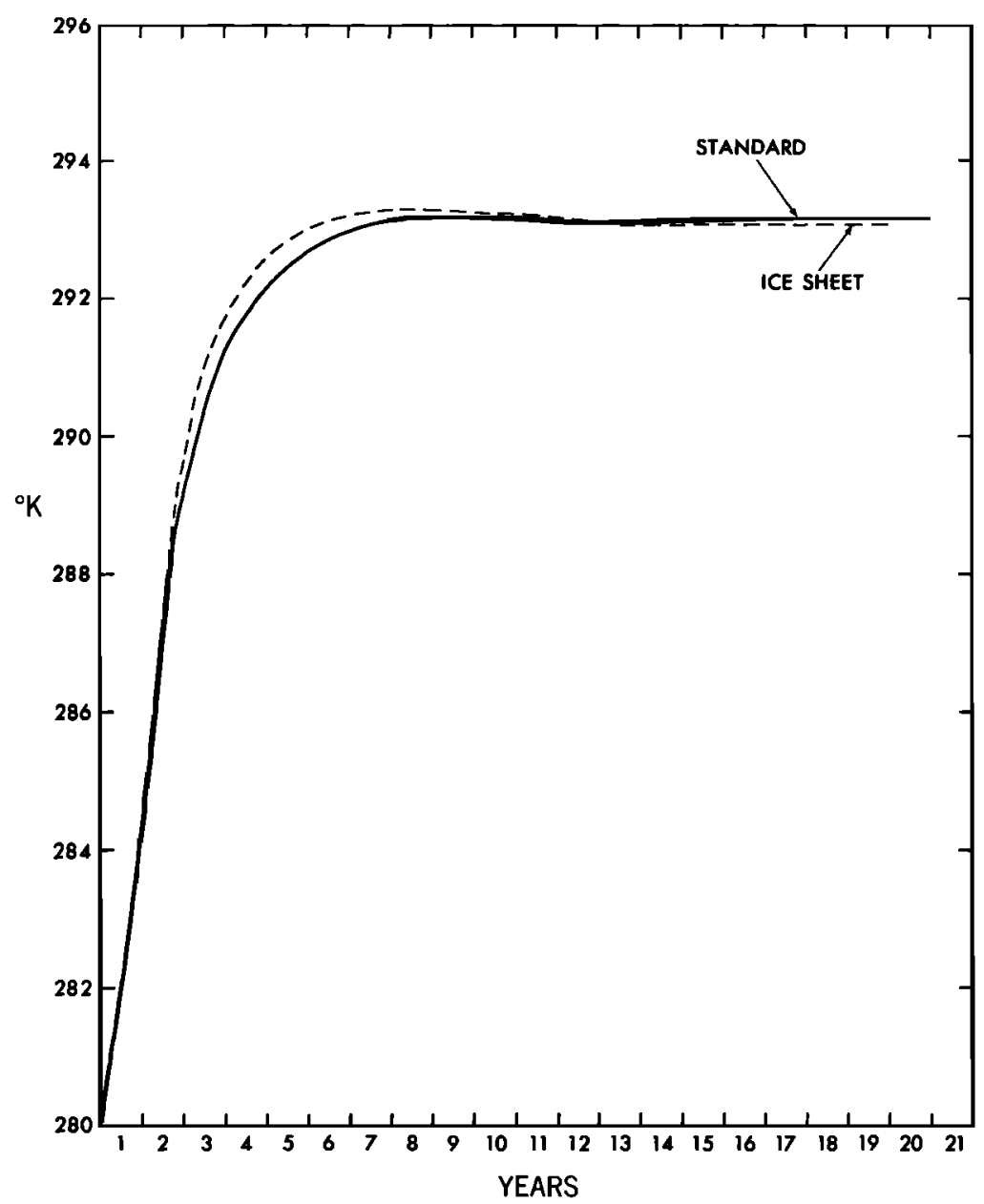

Fig. 3. Time variation of the global mean mixed-layer ocean temperature from the ice sheet and standard experiments. A 1-year, running mean operator is applied to both curves. Because of differences in sea level, the oceanic area is different between the two experiments; therefore the smallness of the difference in area-mean temperature is not representative of the temperature change between the two experiments.

of continental ice at the peak of the last major glaciation at 18K B.P. and will hereafter be identified as the ice sheet experiment. This continental ice distribution represents the "maximum reconstruction" as discussed by Hughes et al. [1981]. The 18K B.P. distribution of continental ice as reconstructed by CLIMAP is reflected in the ice age topography shown in the lower portion of Figure 2.

The topographic maps in Figure 2 are obtained by applying the "rhomboidal 15" spectral truncation to the modern and 18K B.P. surface elevations. Thus they are compatible with the computational resolution of the spectral model used for the present study. Despite this spectral smoothing the major characteristics of the original topographic distributions remain unaltered. A disturbing consequence of the spectral truncation are the spurious ripples of negative altitude in oceanic regions. These ripples are particularly pronounced near the steep coastal slopes of Antarctica and Greenland. The negative altitudes in oceanic regions do not exceed $400 \mathrm{~m}$ at any point and are generally less than $50 \mathrm{~m}$.

The land-sea boundaries indicated in the maps of Figure 2 are not derived from the spectrally truncated topography. Instead, high-resolution topographic data are interpolated to the model grid to obtain land-sea boundaries.

According to the estimate by CLIMAP, the 18K B.P. sea level was about $150 \mathrm{~m}$ below the present sea level because of the exchange of water mass between continental ice sheets and oceans. Therefore the difference in sea level between the two experiments is prescribed to be $150 \mathrm{~m}$.

Orbital parameters in both experiments are set at modern values. This is a reasonable simplification, since the set of orbital parameters at $18 \mathrm{~K}$ B.P. is not very different from the modern set, as noted in section 1 . Thus the distribution of insolation at the top of the atmosphere with latitude and season is the same in both experiments. The same distribution of surface albedo of snow- and ice-free areas is used for both experiments. The albedo of continental ice is the same in both experiments, and the treatment of snow cover and sea ice is the same, as described in section 2.

\section{3b. Numerical Time Integration}

The initial condition for both time integrations is an isothermal and dry atmosphere at rest coupled with an isothermal mixed-layer ocean. The initial temperature is chosen to be $280^{\circ} \mathrm{K}$. The temporal variations of global mean (water) temperature of the mixed-layer ocean from the two experiments are shown in Figure 3. Annual variation is removed from both curves by applying a 1-year running mean operator. According to this figure, the global mean temperature of the mixed-layer ocean of the model changes little after year 12 of both experiments. The detailed analysis of the results from the 


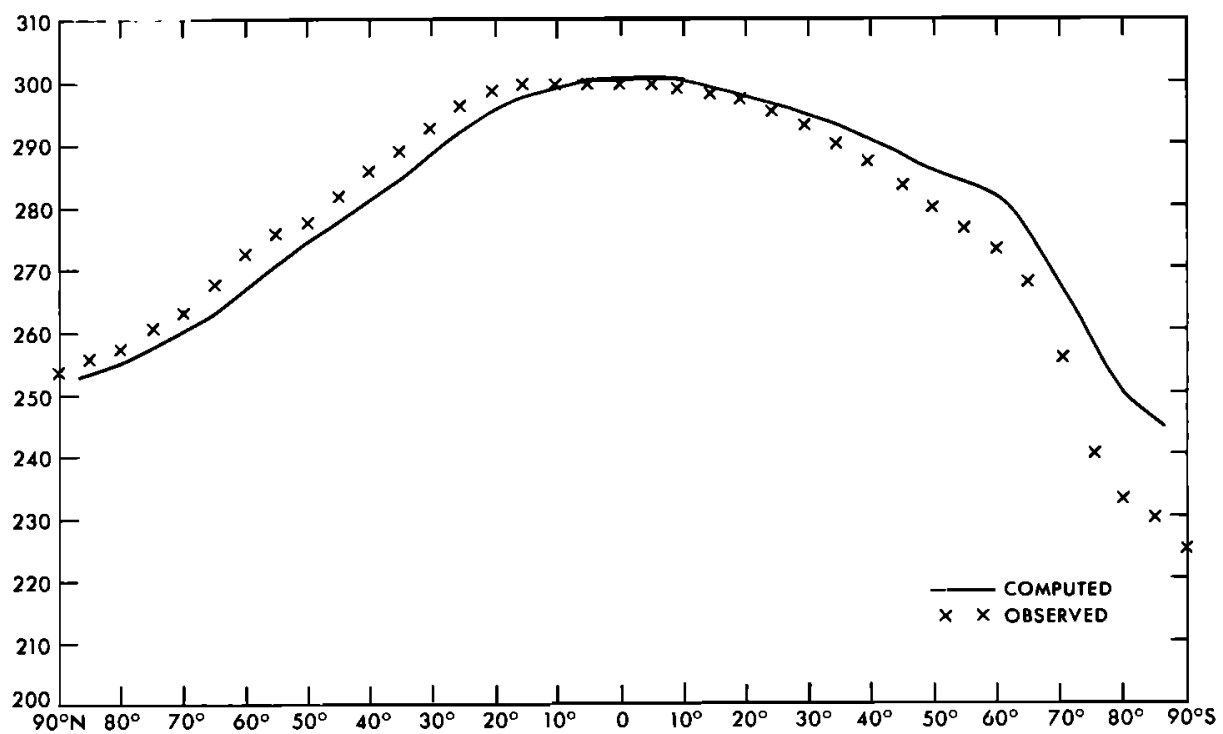

Fig. 4. Latitudinal distribution of annual average zonal mean surface air temperature from the standard experiment (solid line, degrees Kelvin). The observed zonal mean temperatures [Crutcher and Meserve, 1970; Taljaard et al., 1969] are included for comparison and are indicated by crosses.

numerical time integrations, however, indicates that zonal mean temperature distribution of the mixed-layer ocean of the model does not become stationary until several years after the global mean temperature reaches a stationary value. Therefore the results from the last 6 years of the standard experiment and the last 5 years of the ice sheet experiment are used for the analysis described in subsequent sections.

The distribution of climate that emerged from the standard experiment is described in detail by Manabe and Stouffer [1980]. As emphasized in their paper, the model attained a rather realistic climate toward the end of the standard time integration. One notes, however, significant differences between the simulated and actual climates as indicated by Figure 4, which compares the latitudinal distribution of zonally averaged surface air temperature of the model atmosphere with the observed distribution. According to this figure, the zonal mean surface air temperature of the model is slightly lower than the observed temperature in the northern hemisphere, whereas it is significantly warmer than the observed in the southern hemisphere.

Sea ice is somewhat overestimated in extent in the northern hemisphere, particularly in winter. In the southern hemisphere the model substantially underestimates the areal extent of sea ice throughout the year. The differences between the model sea ice distribution and the observed sea ice distributions are consistent with the differences between computed and observed surface air temperature described in the preceding paragraph.

Precipitation is simulated reasonably well by the model, but there are two major inconsistencies with the observed precipitation. The location of the intertropical convergence zone and its accompanying rainbelt is about $5^{\circ}-10^{\circ}$ latitude south of the observed position. This is probably due to hemispheric biases in surface air temperature. In addition the model precipitation at high latitudes is too large throughout the year. It has been noted that this is one of the characteristics of a spectral model of the atmosphere with relatively low computational resolution [Manabe et al., 1979b].

\section{Climate Response}

\section{4a. Sea Surface Temperature}

To illustrate the effect of continental ice on the distribution of sea surface temperature (SST), Figures 5 and 6 are constructed. These figures show the geographical distributions of the SST difference of the model mixed-layer ocean between the ice age and the standard experiments for February and August, respectively. (Note that in the areas covered by sea ice the SST is assumed to be $-2^{\circ} \mathrm{C}$.) For the sake of comparison the distribution of the SST difference between 18K B.P. and the present as determined by CLIMAP is added to the lower half of each figure.

These maps indicate that, during both February and August, the SST difference in the southern hemisphere of the model is very small. On the other hand the difference between the 18K B.P. and modern sea surface temperature estimated by CLIMAP has significant magnitude in not only the northern hemisphere but also the southern hemisphere. Since most of the changes in the distribution of continental ice between the two experiments are located in the northern hemisphere, this result suggests that the existence of an ice sheet in one hemisphere has relatively little influence on the distribution of sea surface temperature in the other hemisphere. This issue is discussed further toward the end of this section.

In the northern hemisphere, SST's from the ice sheet experiment are significantly colder than the corresponding temperatures in the standard experiment. In both February and August the difference is most pronounced in the mid-latitudes of the North Atlantic and the North Pacific. The ice-sheetinduced cooling over the Atlantic is generally larger than the corresponding cooling over the Pacific. This feature is in good qualitative agreement with the difference obtained by CLIMAP between the modern and $18 \mathrm{~K}$ B.P. distributions of SST. Some of the characteristics of the CLIMAP SST differences are not reproduced by the model. For example the model distribution lacks the areas of slight positive SST difference in the subtropical region of the North Pacific and the 

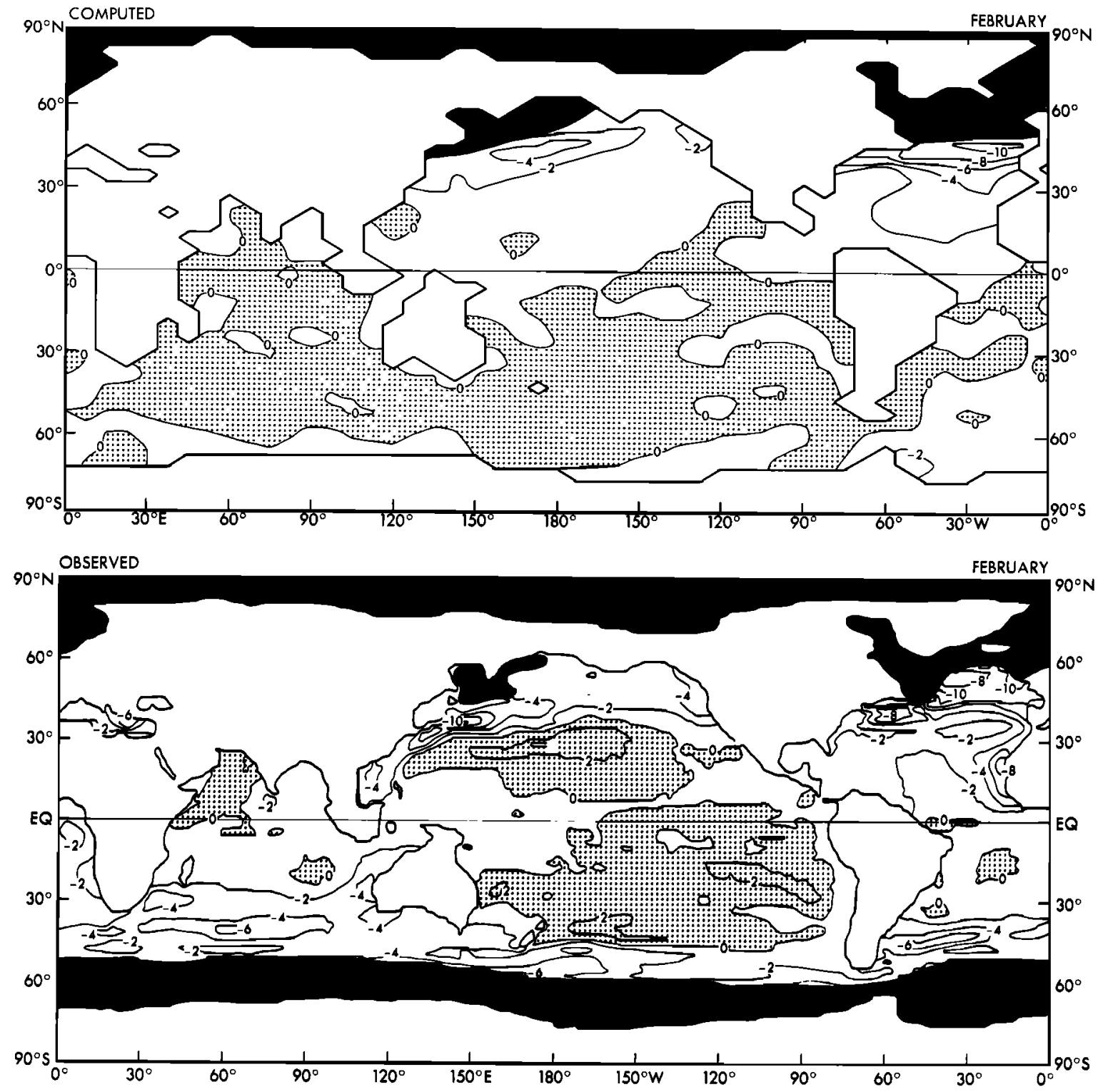

Fig. 5. February monthly mean SST difference (degrees Kelvin, stippling indicates positive difference): (top) difference between ice sheet and standard experiments; (bottom) difference between 18K B.P. and present (as reconstructed by CLIMAP). Areas covered by sea ice in the ice sheet experiment and at 18K B.P. are indicated by black shading.

narrow belt of large negative SST difference located along the east coast of the Eurasian continent. This region of localized negative difference appearing in the CLIMAP result is probably indicative of the shift of the Kuroshio current between the glacial period and the present. Since the simplified mixedlayer ocean of the model does not have the effect of heat transport by ocean currents, it is not surprising that the model fails to reproduce this characteristic.

The zones of maximum difference in sea surface temperature in winter over both the North Atlantic and the North Pacific of the model approximately coincide with the winter sea ice margin from the ice sheet experıment. Since the temperature of water beneath sea ice is prevented from falling below the freezing point (i.e., $-2{ }^{\circ} \mathrm{C}$ ), the meridional gradient of mixed-layer temperature is zero poleward of the sea ice margin, while it is negative equatorward of the sea ice margin. This feature is evident in Figure 7, which includes the latitudinal profiles of zonal mean SST and sea ice thickness over the North Atlantic ocean in winter from both experiments. (For the discussion in section $4 e$ the latitudinal distributions of surface air temperature from the two experiments are also added to the same figure.) The difference between the two zonal mean SST's is at a maximum near the sea ice margin in the ice age experiment and becomes zero poleward of the sea ice margin in the standard experiment. This figure clearly reveals the close relationship between the sea ice margin and the difference in sea surface temperature between the two experiments.

For a quantitative comparison between the results from the model experiments and those obtained by CLIMAP, Figure 8 is constructed. This figure illustrates, for the months of February and August, the zonal mean difference in SST between the ice sheet and standard experiments. In addition the corresponding difference between the $18 \mathrm{~K}$ B.P. and modern SST obtained by CLIMAP is plotted in the same figure. Again, one notes that in the southern hemisphere the SST difference between the two experiments is very small, whereas a significant difference is indicated in the CLIMAP results. The only area in which a substantial reduction in zonal mean SST can be 

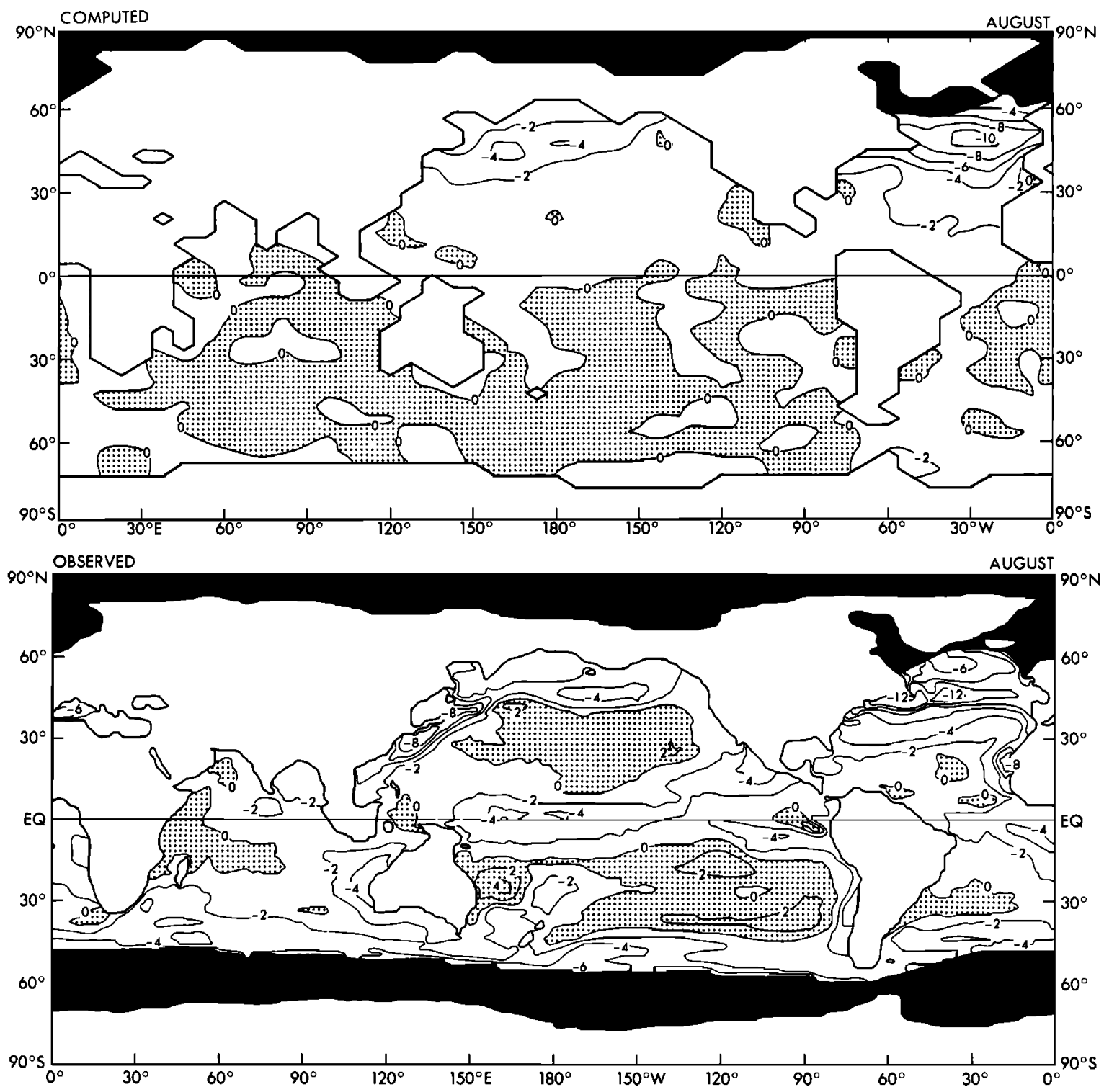

Fig. 6. Same as Figure 5 except for August.

noted in the southern hemisphere is the coastal waters near Antarctica. It is likely that this reduction results from the difference in the horizontal extent of the Antarctic ice sheet between $18 \mathrm{~K}$ B.P. and the present. According to Figure 2, the $18 \mathrm{~K}$ B.P. ice sheet is more extensive than the present one, occupying most of the continental shelves of the Ross and Weddell seas. Elsewhere, southern hemisphere zonal mean SST for the ice age experiment is slightly warmer than the corresponding temperature for the standard experiment. This slight warming probably results from the ice-sheet-induced increase of sea level pressure which occurs in response to the lowering of sea level and displacement of atmospheric mass by the ice sheets. This increases the optical depth (for terrestrial radiation), enhancing the greenhouse effect of the atmosphere. This speculation is supported by the results from a numerical experiment using a one-dimensional, radiative-convective model of the atmosphere in which a 15 -mbar increase in sea level pressure produces an increase in surface temperature of $0.04 \mathrm{~K}$. The main implication of the present results is however, that the thermal influence of the northern hemisphere upon the sea surface temperature of the southern hemisphere is small.

In the northern hemisphere the belt of the largest SST difference produced by the model is located to the south of the corresponding belt in the CLIMAP results. This is the case for both February and August. As pointed out earlier in the discussion of the geographical distribution of SST difference between the ice sheet and standard experiments, the belt of the largest difference is located near the winter sea ice margin in the ice sheet experiment. Since the northern hemisphere SST as simulated by the model is colder than the observed temperature as pointed out in section 3 , the simulated sea ice margin is placed equatorward of its observed position. This explains why the belt of the largest temperature difference is placed equatorward of the belt of maximum difference between $18 \mathrm{~K}$ B.P. and present SST as estimated by CLIMAP.

These discussions are substantiated by Figure 9, in which zonally averaged northern hemisphere SST differences are plotted against the sea surface temperature of the standard experiment rather than latitude. In this figure the largest SST 


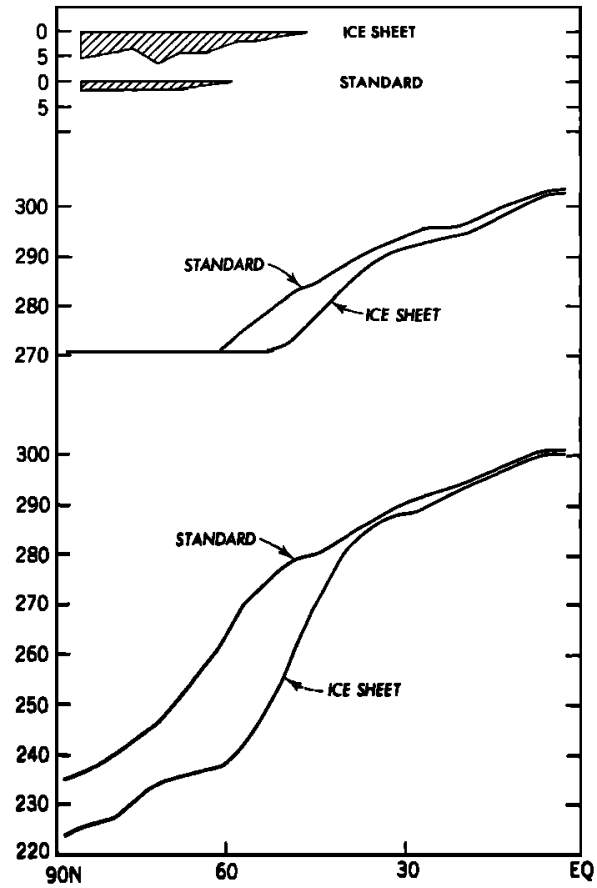

Fig. 7. Latitudinal distributions of some zonally averaged atmospheric and oceanic parameters for the North Atlantic Ocean during winter from the ice sheet and standard experiments: (top) sea ice thickness in meters; (middle) sea surface temperature in degrees Kelvin; (bottom) surface air temperature in degrees Kelvin.

difference between the ice sheet and standard experiments occurs approximately at the same temperature as the largest SST difference between 18K B.P. and the present as estimated by CLIMAP. This figure suggests that, if the sea surface temperature in the northern hemisphere of the model were simulated more realistically, the agreement between the computed and CLIMAP profiles of SST difference in the northern hemisphere would have been better.

\section{4b. Flow Field}

From the discussion in the preceding subsection it is clear that the zonal belt of large SST difference in the North Atlantic Ocean of the model is a manifestation of the equatorward shift of the margin of sea ice from the standard to the ice sheet experiment. The physical mechanism responsible for the shift becomes evident when one examines the winter distribution of atmospheric flow as obtained from the ice sheet experiment.

Figure 10 contains maps of the geopotential height at the 515-mbar surface averaged over the December-JanuaryFebruary season (i.e., northern hemisphere winter) for the ice sheet and standard experiments. This figure indicates that the 515-mbar geopotential height field from the ice sheet experiment is characterized by (1) an intense ridge over western North America, (2) a long-wave trough in eastern North America tilted from southwest to northeast, and (3) a ridge located along the west coast of Europe. Examining the distribution of wind speed at the 515-mbar level shown in Figure 11, a split flow structure is present straddling the Laurentide ice sheet. The northern wind maximum, by far the weaker of the two, possesses an anticyclonic curvature over the northwestern portion of North America. On the other hand the southern branch becomes very intense on the downstream side of the eastern North American trough described above.

Although one can identify qualitatively similar character- istics in the field of 515-mbar geopotential height from the standard experiment, the pattern is much less pronounced. No split flow structure exists, and the single jet present is considerably weaker than the southern branch jet from the ice sheet experiment. Thus it is clear from this comparison that the North American ice sheet is responsible for creating a split flow and intensifying the eastern North American trough at mid-tropospheric levels.

The pattern of 515-mbar geopotential height from the ice sheet experiment can be compared with the surface flow field shown in Figure 12. Beneath the strong mid-tropospheric ridge over northwestern North America, a region of anticyclonic outflow is present at the surface. An intense surface flow originates from this anticyclone and follows the northern periphery of the North American ice sheet, eventually passing between the Laurentide and Greenland ice domes and over the Labrador Sea. This parallels the route of the northern branch of the mid-tropospheric split flow. The northern slope of the ice sheet, with its high reflectivity, provides an ideal environment for the development of the extremely cold air masses which invade the North Atlantic Ocean. This cold air is responsible for the formation of thick sea ice which, in turn, reduces the heat exchange between the sea water and the overlying air and prevents the warming of the air mass. This self-sustaining mechanism will be discussed further in the following subsection.

\section{4c. Surface Air Temperature}

The geographical distribution of the difference in the surface air temperature between the ice sheet and standard experiments is illustrated in Figure 13 for the December-JanuaryFebruary (DJF) and June-July-August (JJA) seasons. (Computed "surface air temperature" is the temperature at the lowest finite-difference level of the model, which is located $\sim 70 \mathrm{~m}$ above the earth's surface.) Since the response of the surface air temperature is different for oceanic and continental areas, it is discussed separately for oceans and continents.

Oceans. During the DJF season, one notes the belt of large negative surface air temperature difference over the North Atlantic Ocean at about $50^{\circ} \mathrm{N}$, with a magnitude of more than $30^{\circ} \mathrm{C}$ over the Labrador Sea. A similar belt of large negative surface air temperature difference is also present in the western North Pacific at approximately the same latitude but of less magnitude than its Atlantic counterpart. As discussed in the preceding subsection, an extremely cold surface air mass is developed over the northern periphery of the North American ice sheet and flows over the North Atlantic Ocean in the ice sheet experiment. This accounts for the North Atlantic maximum of surface air temperature difference described above. It is of interest that over both the North Atlantic and North Pacific oceans the magnitude of the DJF difference in surface air temperature is much larger than the corresponding SST difference.

The physical mechanism responsible for this large difference in the surface air temperature becomes evident from the analysis of Figure 7. The top part of this figure illustrates the distributions of zonal mean sea surface temperature for the Atlantic Ocean from both the standard and ice sheet experiments. The bottom part of Figure 7 contains the latitudinal distributions of surface air temperature from the two experiments. The distribution of zonal mean sea ice thickness is also shown in the upper part of the figure for reference. In both experiments the zonal mean air-sea temperature difference increases sharply from the margin of sea ice toward higher latitudes, where sea 

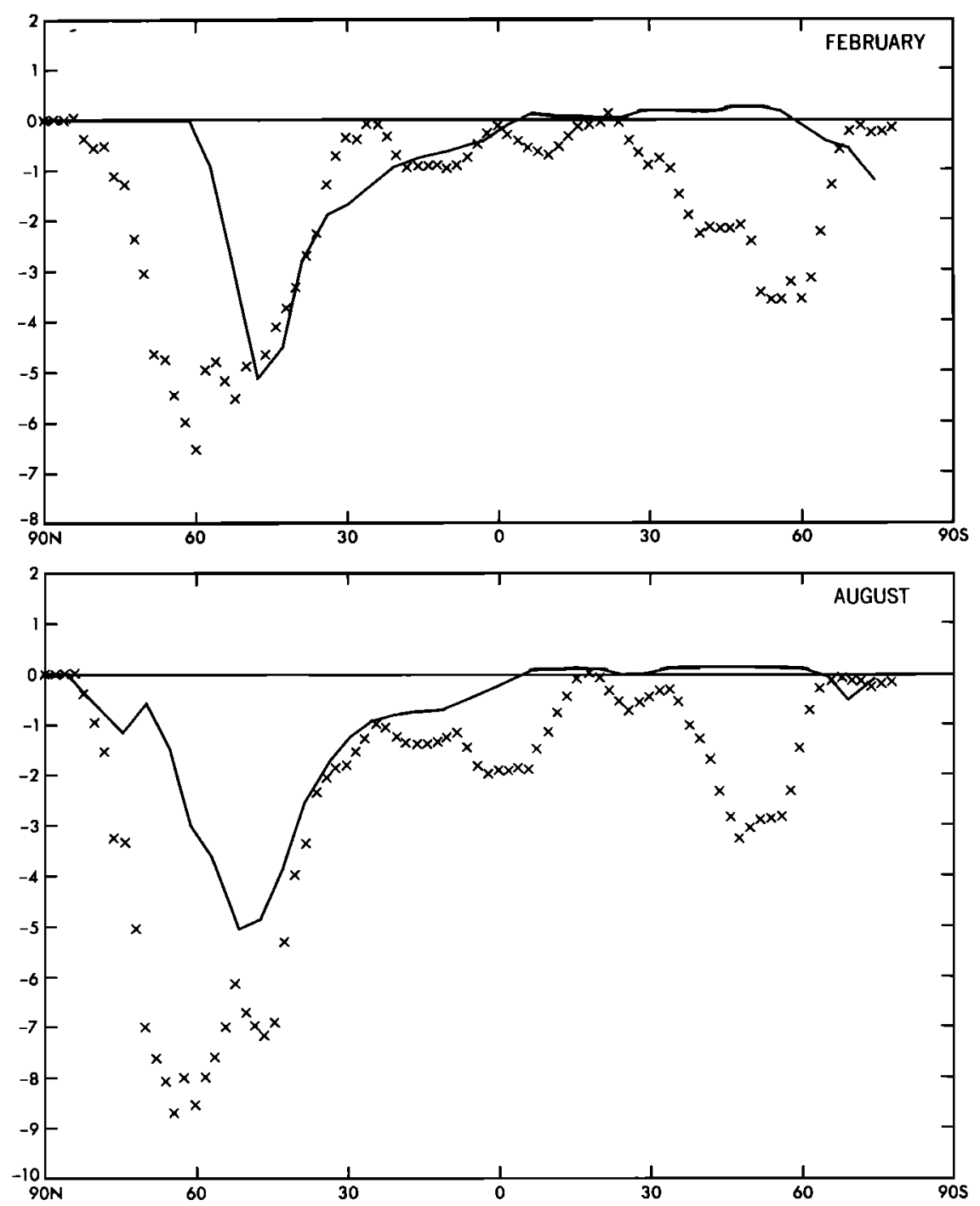

Fig. 8. Latitudinal distribution of zonal mean SST difference between the ice sheet and standard experiments (degrees Kelvin). Zonal averages are computed by using only grid points that represent oceans in both experiments. The SST differences between 18K B.P. and present as reconstructed by CLIMAP are included for comparison and are indicated by crosses: (top) February; (bottom) August.

ice is thicker and heat exchange between the ocean and the overlying air is reduced. Since the sea ice margin in the ice sheet experiment is located to the south of the sea ice margin in the standard experiment, one can identify in this figure a zonal belt between $47^{\circ} \mathrm{N}$ and $60^{\circ} \mathrm{N}$ where sea ice exists only in the ice sheet experiment. In this zonal belt the air-sea temperature difference in the ice sheet experiment is much larger than the corresponding difference in the standard experiment because of the insulating effect of sea ice. This is why the difference in surface air temperature between the two experiments is very large just to the north of the sea ice margin in the ice sheet experiment as indicated in the upper half of Figure 13.

In the JJA season the air-sea temperature difference is small over both the North Atlantic and North Pacific oceans of the model in both experiments. Therefore the distribution of the difference in surface air temperature between the two experiments is essentially similar to the distribution of SST difference discussed in the preceding section.

Continents. As Figure 14 indicates, the difference in zonal mean surface air temperature between the two experiments undergoes large seasonal variation over the continents. Over both the North American and Eurasian continents, the difference in winter is much larger than the corresponding difference in summer. In winter the region of large difference extends from the southern periphery of continental ice sheets toward subtropical latitudes, where in summer it is limited to the immediate vicinity of ice sheets.

Figure 15 illustrates the latitude-time distribution of the difference in zonal mean albedo of the continental surface between the two experiments. The difference is large in winter and small in summer in the middle latitude region south of the ice sheets. This seasonal variation of the difference in surface albedo is partly responsible for the large seasonal dependence of the surface air temperature difference described above. The winter snow cover in the ice sheet experiment is much more extensive than the corresponding snow cover in the standard experiment. This partly accounts for the large difference in surface albedo in winter. On the other hand the difference in snow cover between the two experiments is small during summer when there is little snow to the south of ice sheets.

The difference in surface air temperature between the ice sheet and standard experiments can be compared with paleo- 

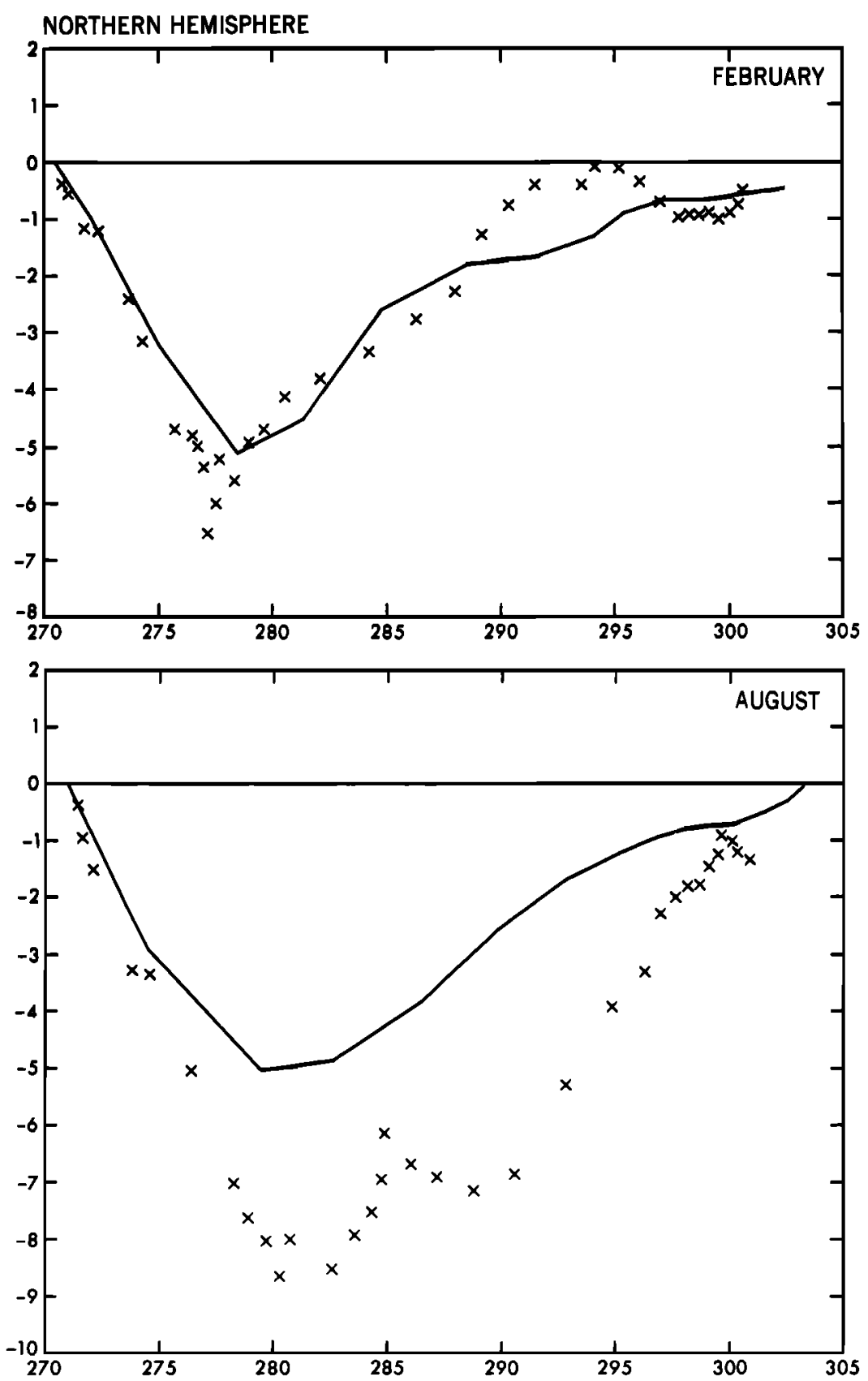

Fig. 9. Zonal mean SST differences between the ice sheet and standard experiments plotted against the zonal mean SST of the standard experiment over the northern hemisphere (solid line). The SST differences between 18K B.P. and present as reconstructed by CLIMAP plotted against present zonal mean SST are indicated by crosses. All temperatures are in degrees Kelvin : (top) February; (bottom) August.

climatic estimates of the temperature difference between $18 \mathrm{~K}$ B.P. and the present. The estimates used are extracted from the compilation of paleobotanical and other geological data by Peterson et al. [1979]. In selecting the data to be used in this comparison, all of the paleotemperatures mapped by Peterson et al. are used irrespective of differences in the precision of the dating. Figure 16 contains a pair of scatter diagrams that illustrate the correspondence between these paleoclimatic temperature differences and the temperature differences from the nearest model grid point for various geographical locations in the northern hemisphere. When more than one paleotemperature is available in a single computational grid box of the model, an arithmetic average of all paleotemperatures within the box is computed and plotted to avoid overrepresentation of any individual geographic region. Figure 16 contains diagrams for annual mean and July surface air temperatures. Since very few paleoclimatic estimates of surface air temperature are available for winter, a similar diagram is not constructed for that season.

As illustrated in this figure, the differences in computed surface air temperature between the two experiments are substantially smaller than the paleoclimatic estimates of the difference between the $18 \mathrm{~K}$ B.P. and present surface air temperature. In the case of annual mean data the lack of correspondence is particularly large for locations from 0 to $40^{\circ} \mathrm{N}$ and less substantial in higher latitudes. During summer, the computed 

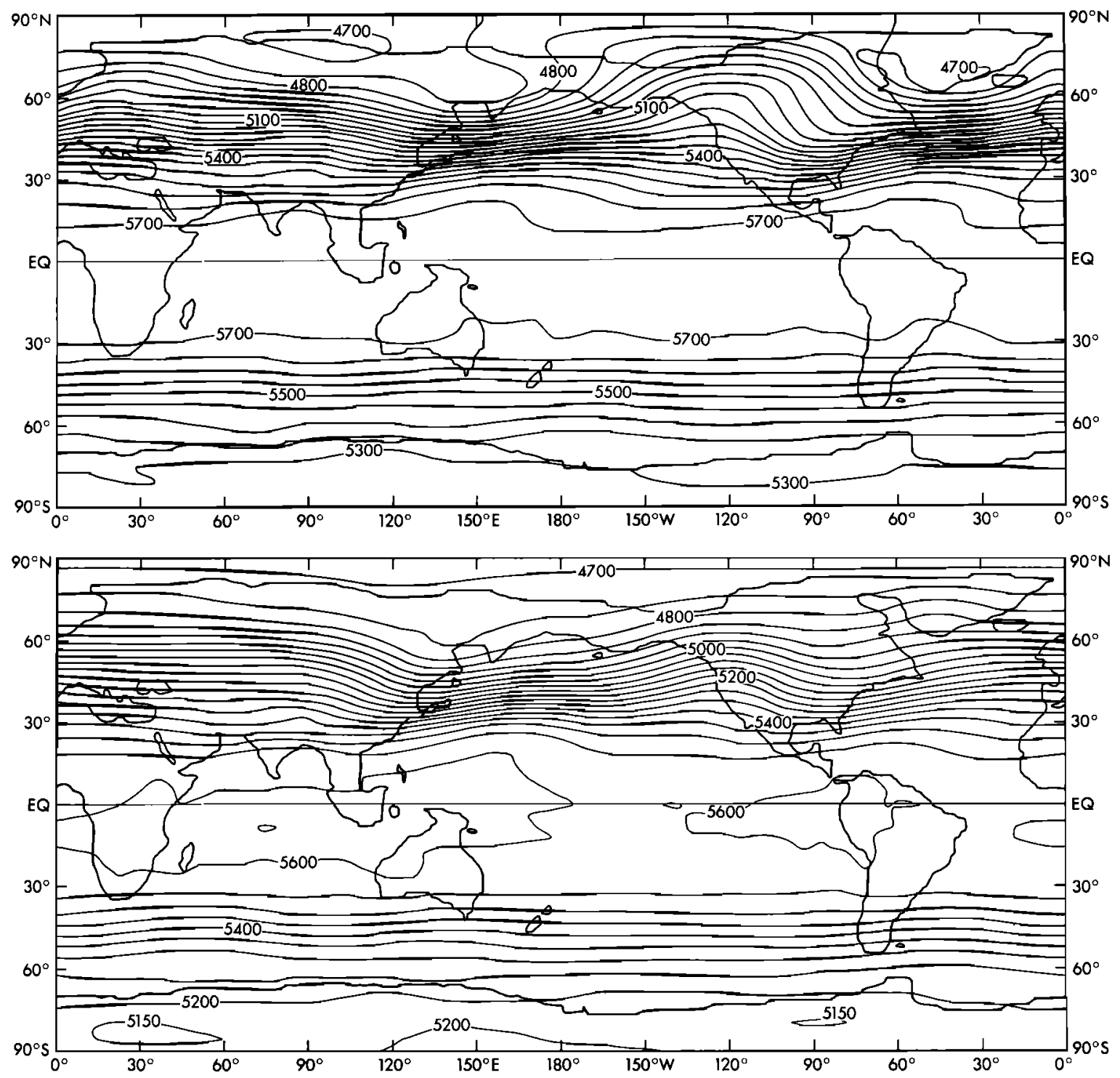

Fig. 10. December-January-February (DJF) 515-mbar geopotential height (meters): (top) ice sheet experiment; (bottom) standard experiment.

temperature difference is too small throughout the locations sampled, with a discrepancy in the sign of the temperature difference at several locations. In summary the computed icesheet-induced cooling of surface air temperature over the continents in summer is small and is much less than the corresponding cooling in winter. This contrasts with the difference between the 18K B.P. and modern temperatures as estimated from paleobotanical and geologic evidence, which are comparable in magnitude for both seasons.

The results from the recent study by CLIMAP suggest that, in general, the $18 \mathrm{~K}$ B.P. albedo of snow (or ice)-free continental surfaces is significantly larger than the modern albedo. These differences are attributed to the lighter color of glacial soils and a reduced density of vegetational cover at the last glacial maximum [CLIMAP Project, 1981]. The higher surface albedo may be responsible for the lower 18K B.P. surface air temperature over the continents in summer, when the land surface is almost snow-free equatorward of the continental ice sheets. Since the identical distribution of surface albedo is prescribed for the snow (or ice)-free continents in both experiments of this study, the absence of this albedo change may be the reason why the summer difference in surface air temperature between the two experiments is relatively small.

In this regard the results from the numerical simulations of an ice age climate conducted by Gates $[1976 a, b]$ and Manabe and Hahn [1977] are relevant. By prescribing the distributions of continental ice, SST, and surface albedo determined by the CLIMAP Project [1976], they were able to produce generally large differences in summer surface air temperature between their ice age and standard experiments. Heath [1979] found generally good agreement between these model results and paleoclimatic temperature data. The results of these studies suggest that higher surface albedo may indeed be responsible for the low 18K B.P. surface air temperature over continental regions in summer. In order to confirm this speculation it is necessary to conduct a set of numerical experiments designed to determine the sensitivity of the model climate to changes in surface albedo.

\section{4d. Hemispheric Heat Balance}

In the preceding subsections it is shown that the massive continental ice sheets of the $18 \mathrm{~K}$ B.P. ice age have little influ- 

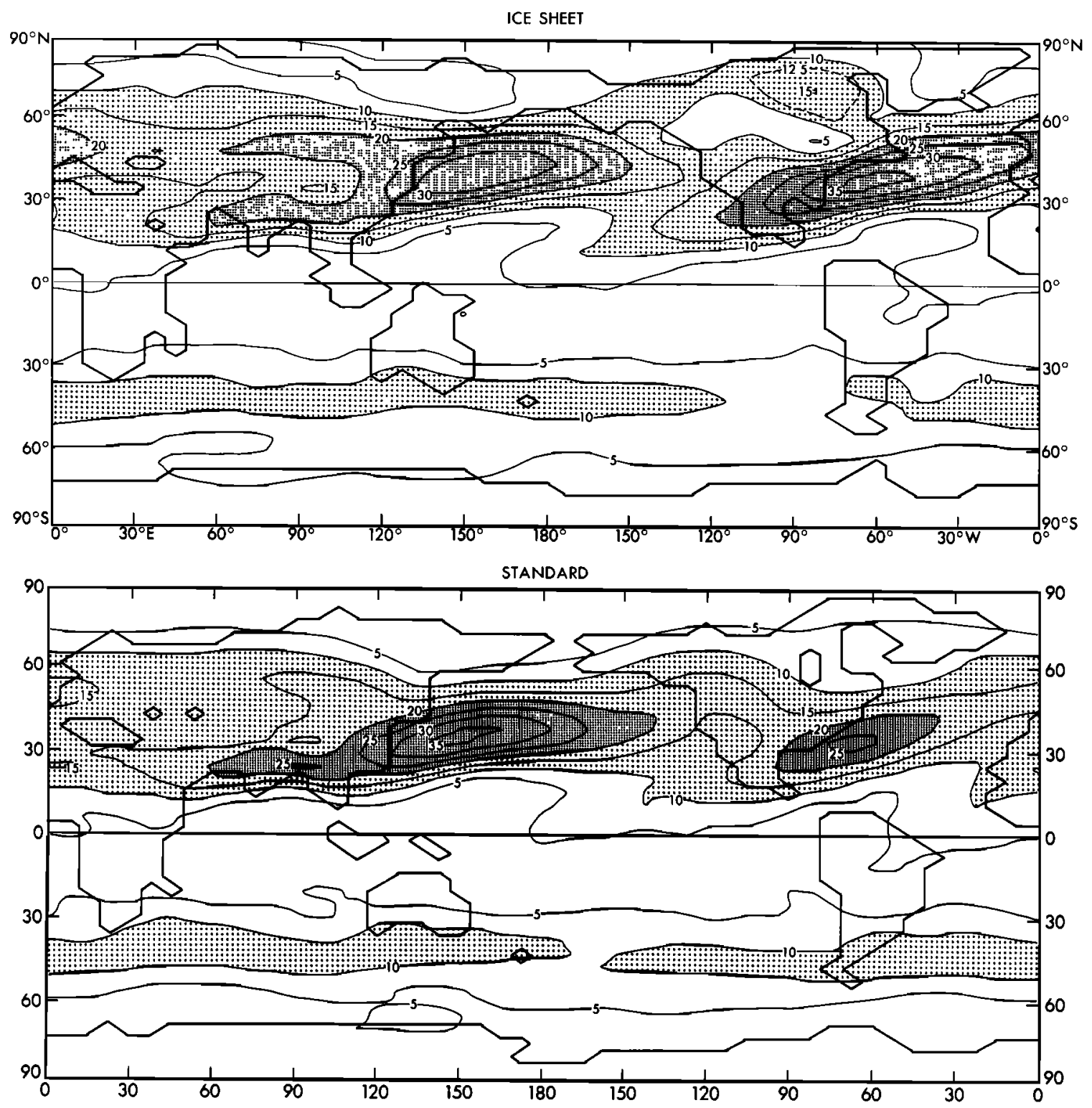

Fig. 11. Wind speeds for the DJF season at the 515 -mbar level ( $\mathrm{m} \mathrm{s}^{-1}$ ): (top) ice sheet experiment; (bottom) standard experiment.

ence upon southern hemisphere temperature in the atmosphere-mixed layer ocean model. In order to evaluate this result the annual mean hemispheric heat budgets of the model atmosphere are obtained from the standard and ice sheet experiments. These are illustrated by the box diagrams in Figure 17, as is the difference in heat budget between the two experiments.

For the northern hemisphere this figure indicates that the net downward flux of solar radiation at the top of the model atmosphere in the ice sheet experiment is $5.6 \mathrm{~W} \mathrm{~m} \mathrm{~m}^{-2}$ less than the corresponding flux in the standard experiment. This is primarily due to the reflection of insolation by the large area of continental ice. This difference in incoming solar radiation is essentially counterbalanced by a difference of $5.8 \mathrm{~W} \mathrm{~m}^{-2}$ in outgoing terrestrial radiation at the top of the model atmosphere. Although the rate of interhemispheric heat exchange is also different in the two experiments, the magnitude of the difference is only $0.4 \mathrm{~W} \mathrm{~m}^{-2}$ and is much smaller than the differences in the net incoming solar radiation and outgoing terrestrial radiation mentioned earlier.

These results indicate that in the ice sheet experiment the reflection of incoming solar radiation reduces the surface temperature in the northern hemisphere of the model and, accordingly, the outgoing terrestrial radiation at the top of the atmosphere. The relatively low surface temperature in the northern hemisphere induces a small change in the heat exchange between the two hemispheres. However, the in situ radiative compensation in the northern hemisphere is much more effective than the thermal adjustment through the interhemispheric heat exchange in the model atmosphere.

In order to examine further the difference in the interhemispheric exchange of heat between the two experiments the latitudinal distributions of the annual mean northward transport of moist static energy by the model atmosphere is plotted in Figure 18 for both the standard and ice age experiments. Here the moist static energy is defined as

moist static energy = dry static energy + latent energy

where

$$
\begin{gathered}
\text { dry static energy }=C_{p} T+\phi \\
\text { latent energy }=L r
\end{gathered}
$$




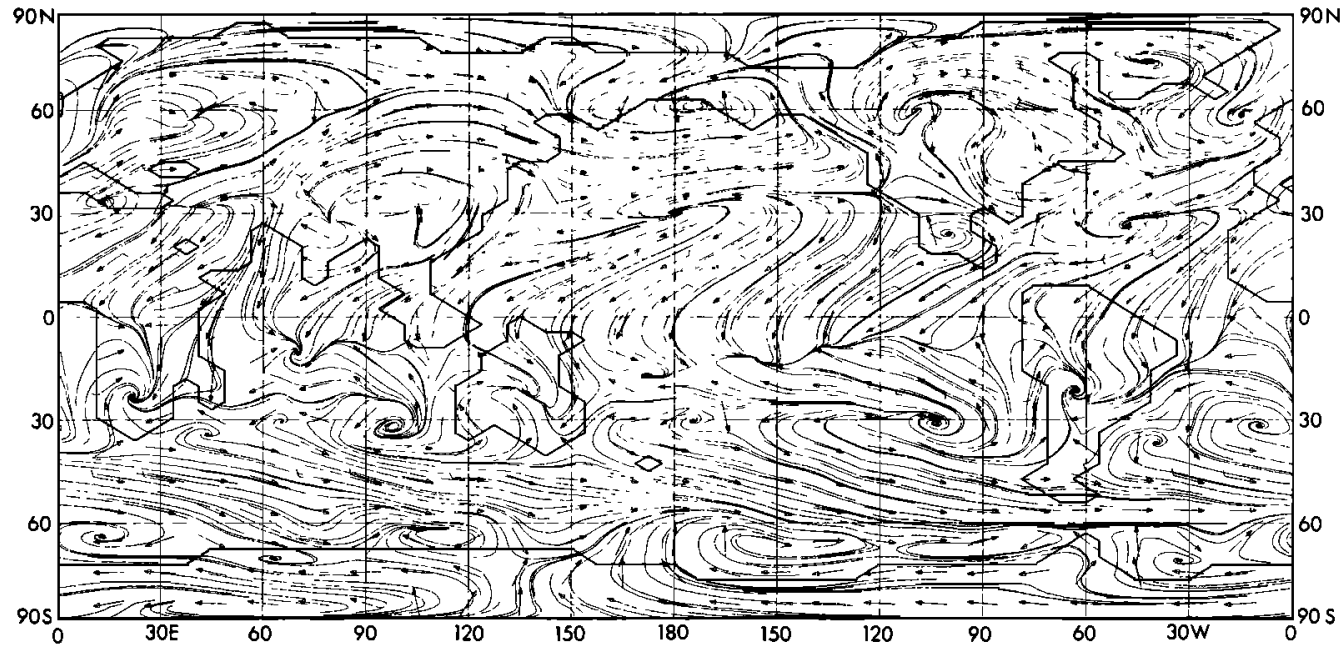

Fig. 12. Surface wind vectors and streamlines for the DJF season from the ice sheet experiment. (Each tail on wind arrows represents $5 \mathrm{~m} \mathrm{~s}^{-1}$.)

Here, $C_{p}$ is the specific heat of air under constant pressure, $L$ is latent heat of condensation, $T$ is the absolute temperature, $\phi$ is geopotential height, and $r$ is the mixing ratio of water vapor in air. The lower portion of the figure shows, on a magnified scale, the difference between the transports from the two experiments broken down into two subcomponents (i.e., dry static energy and latent energy). In this figure one notes northward heat transport of significant magnitude at the model equator. It is likely that this cross-equatorial transport results from the warm bias in the southern hemisphere of the model described earlier.

Figure 18 indicates that the difference in the northward transport of moist static energy between the two experiments is small and is found primarily north of $15^{\circ} \mathrm{S}$. In middle latitudes of the northern hemisphere of the model the increased northward transport of dry static energy in the ice sheet experiment is counterbalanced by the decrease in the latent energy transport. The difference in the poleward transport of dry static energy is largely attributable to the increase in eddy heat transport in the ice sheet experiment caused by the increased meridional temperature gradient. On the other hand the colder temperature of the ice sheet experiment is responsible for a lower atmospheric moisture content and, accordingly, the reduction of the poleward transport of latent heat.

In the tropical region of the model the increase in the northward transport of dry static energy in the ice sheet experiment is partly compensated by the decrease in the transport of latent heat of approximately the same magnitude. These opposing changes are caused by the change in intensity of the cross-equatorial Hadley circulation. As a result the net contribution of these differences to the overall difference in the northward transport of moist static energy turns out to be small, particularly in the model tropics. Therefore the southern hemisphere temperature of the atmosphere-mixed layer ocean model is hardly affected by the inclusion of the $18 \mathrm{~K}$ B.P. ice sheets as described previously.

The results of this subsection suggest that it is necessary to look for mechanisms other than interhemispheric exchange of heat in the atmosphere in order to explain the low temperature of the southern hemisphere during the 18K B.P. ice age [Neftel et al., 1982]. Some of these mechanisms may include a change in the interhemispheric heat transport by ocean currents and the fluctuation of the atmospheric concentration of carbon dioxide. These possibilities are discussed in the concluding section of this paper.

It has been noted that a spectral model with a relatively low resolution such as the present model produces a Hadley cell which is weaker than the observed. Thus the ice-sheet-induced change in the intensity of the cross-equatorial heat transport may be underestimated in the present study. It is therefore desirable to repeat a similar set of experiments by use of a model with higher spectral resolution. However, it is not likely that an improved simulation of the equatorial Hadley cell could have a substantial impact upon the sensitivity of southern hemisphere temperature to continental ice sheets. In view of the smallness of the ice-sheet-induced change in crossequatorial heat transport resulting from the compensation between the transport of dry static energy and latent heat discussed earlier, it is expected that the ice-sheet-induced change in the cross-equatorial transport of moist static energy would remain small despite an increase in the computational resolution of the model.

\section{4e. Ice Budget}

Although the mass budget of ice sheets in the ice sheet experiment is analyzed in this subsection, it should be noted that ice sheet topography is fixed throughout the course of the numerical time integration. Nevertheless, various components of the ice budget at the ice surface are computed for the present analysis.

The mass budget of a continental ice sheet can be determined by area averaging the positive contribution due to accumulation and the negative contribution due to ablation. In evaluating the mass budgets of the North American and Eurasian ice sheets for the ice sheet experiment, the accumulation is taken to be equal to the snowfall, while the ablation processes considered are sublimation from the ice surface and surface melt. In this ice budget analysis it is assumed that all meltwater runs off without refreezing.

Table 2 contains area-averaged annual mean values of snowfall, sublimation, and surface melt for the North American and Eurasian ice sheets. It is evident that the negative contribution from surface melt and sublimation far exceeds the positive contribution from snowfall, implying a net depletion of ice for both ice sheets. Of the two ablation processes the surface melt is larger than the sublimation by a factor of 5 , 

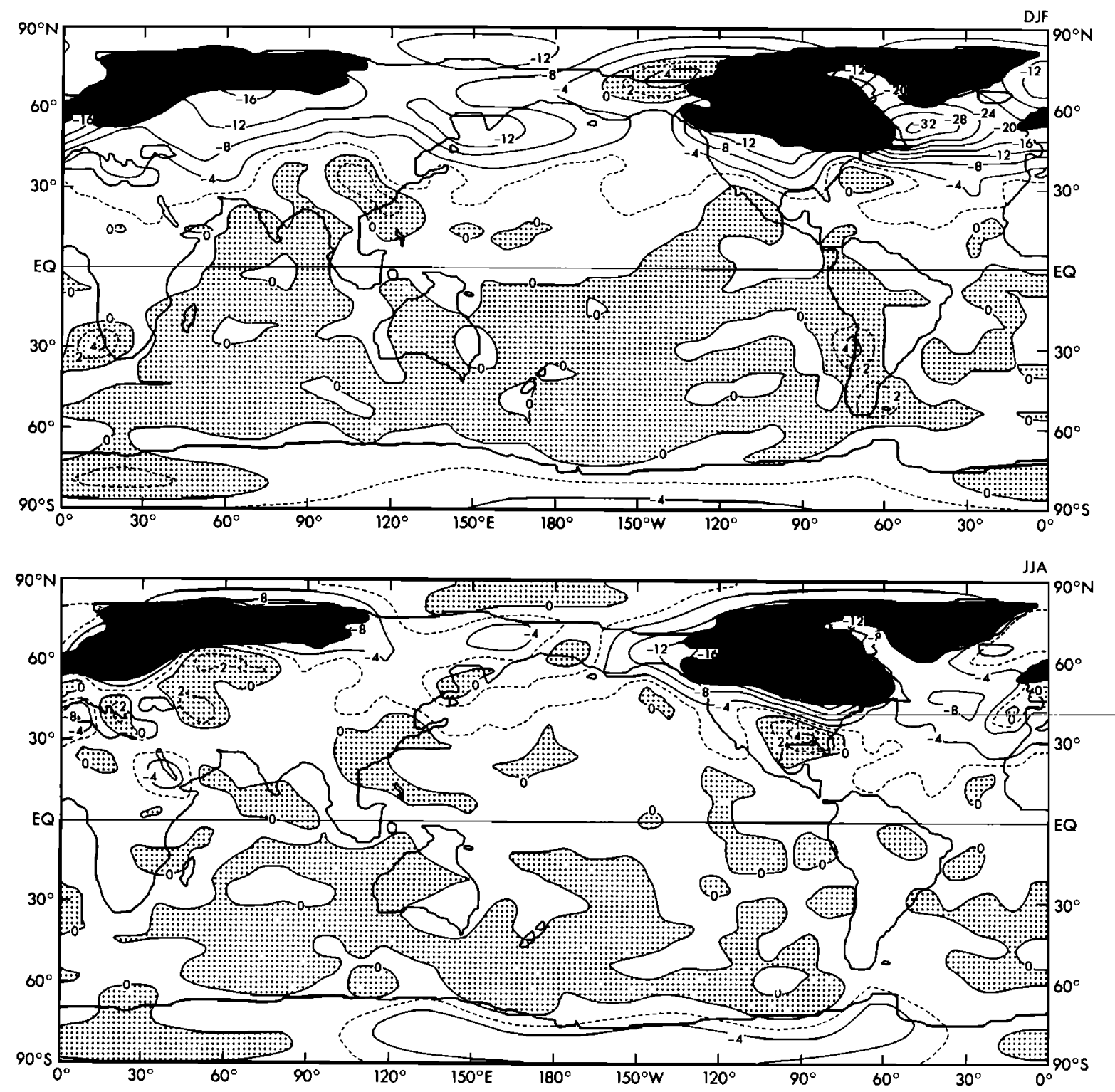

Fig. 13. Difference in surface air temperature between the ice sheet and standard experiments (degrees Kelvin, stippling indicates positive difference): (top) DJF; (bottom) JJA.

being by far the most important term in the ice budget. Comparing the two ice sheets, one notes that the contribution from sublimation is comparable, but the snowfall is smaller and the surface melt is larger for the Eurasian ice sheet. These factors result in a more rapid depletion rate for the Eurasian ice sheet.

The seasonal variation for the ice budget averaged over the entire North American ice sheet is illustrated in Figure 19. This figure indicates that the area-averaged snowfall rate varies little with season, while the sublimation rate undergoes a modest seasonal variation with a winter maximum. In contrast the area-averaged surface melt experiences an extremely large seasonal variation. Little or no surface melt occurs from November through March, but very large values occur during the warm season.

Figure 20 illustrates the geographical distribution of the annually averaged net accretion of ice over both ice sheets. An extremely rapid depletion of ice occurs in a relatively narrow belt along the southern margin of both ice sheets, while a slow accretion takes place over the remaining portions. The processes responsible for the rapid surface melt become evident when one examines the heat budget of an ice sheet. Figure 21 illustrates, as an example, the latitudinal distributions of zonally averaged annual mean values of various heat budget components at the surface of the North American ice sheet. Near its southern margin, where the most rapid surface melt occurs, the ice sheet gains heat through a large downward flux of sensible heat. This is mainly due to the development of intense temperature inversions near the cold surface of the ice sheet during the warm season. It is of interest to note that the ice sheet also gains heat in this region during summer through the downward flux of latent heat (i.e., the condensation of water vapor into dew). This suggests that the air is relatively humid near the ice surface.

In this discussion of the surface heat budget it is important to note that the albedo of the continental ice surface is assumed to be uniform and $70 \%$. Observations have indicated, however, that the surface albedo of melting ice is usually lower than $70 \%$. Had a lower value of surface albedo been used in this experiment, the rate of surface melt along the southern margin of the ice sheet would have been even larger than the 


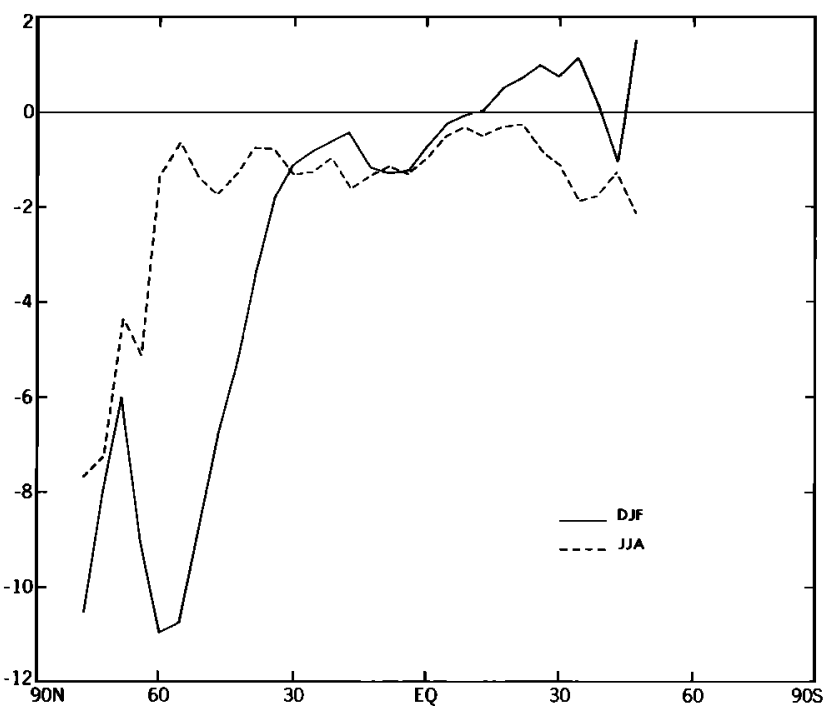

Fig. 14. Latitudinal distribution of the zonal mean difference in surface air temperature at ice-free land points between the ice sheet and standard experiments for the DJF and JJA seasons (degrees Kelvin). Zonal averages are computed by using only grid points that represent ice-free land in both experiments.

rate indicated in Figure 20. Thus the net depletion of the ice sheets would have been much faster.

The results from these ice budget calculations suggest that both ice sheets would deplete very rapidly in the model climate produced in the ice sheet experiment. The relatively small, ice-sheet-induced reduction of surface air temperature over the continents in summer (discussed previously) may account for this net depletion. If the effects of higher surface albedo of snow (or ice)-free continental surfaces and lower $\mathrm{CO}_{2}$ concentration are incorporated into the model, the atmospheric temperature may significantly decrease and reduce the rate of ice sheet depletion.

\section{4f. Hydrology}

In previous subsections it has been shown that the incorporation of continental ice sheets into a model of the atmosphere-mixed layer ocean system produces substantial changes in temperature and atmospheric circulation. Thus it is reasonable to assume that these large ice sheets also have an influence on model hydrology. In this subsection the ice-sheetinduced changes in two particular hydrologic quantities are considered: soil moisture and snowfall.
Soil Moisture. Ice-sheet-induced changes in soil moisture are of interest, since they can provide some insights into changes in the geographical distribution of vegetation types between glacial and interglacial periods. In addition, soil moisture changes can be inferred from botanical and geological evidence of past glacial climates, allowing a comparison with model results. Figure 22 illustrates the geographical distribution of the percentage change in annual mean soil moisture between the standard and ice sheet experiments. (As discussed in the figure caption, no contours are drawn in regions of soil moisture increase.) Large areas in the middle and high latitudes of the northern hemisphere have substantially reduced soil moisture in the ice sheet experiment.

Because of the great spatial and temporal variability of soil moisture, difficulty arises in assessing the importance of these changes in soil moisture. To facilitate the evaluation of the statistical significance of these changes, an application of the Student's $t$ test is used. In this test the $t$ value is computed from the following formula:

$$
t=\frac{\Delta w}{\sigma_{\Delta}}
$$

where $\Delta w$ is the difference in the time-averaged soil moisture between the ice sheet and standard experiments, and $\sigma_{\Delta}$ is the standard deviation of the difference $\Delta w$. Assuming that the time-averaged soil moisture values from each year are independent and have nearly a normal distribution, $\sigma_{\Delta}$ may be computed by the following equation [Panofsky and Brier, 1958]:

$$
\sigma_{\Delta}=\left(\frac{\left(N_{1}-1\right) \sigma_{1}{ }^{2}+\left(N_{2}-1\right) \sigma_{2}{ }^{2}}{N_{1}+N_{2}-2} \cdot\left(\frac{1}{N_{1}}+\frac{1}{N_{2}}\right)\right)^{1 / 2}
$$

where $N_{1}$ and $N_{2}$ are the sample sizes (i.e., the number of years) from the ice sheet and standard experiments; $\sigma_{1}$ and $\sigma_{2}$ are the standard deviations of the soil moisture values from the two experiments.

This procedure is carried out for each model grid point that represents ice-free land. The geographical distribution of locations of which the sign of the difference in soil moisture between the two experiments is statistically significant at the 95\% level is shown in Figure 23. The light shading represents areas in which the soil moisture is lower in the ice sheet experiment, while the dense shading represents areas in which it is higher. In the unshaded land areas the soil moisture difference is not significantly different from zero.

In comparing Figures 22 and 23, one notes that some areas

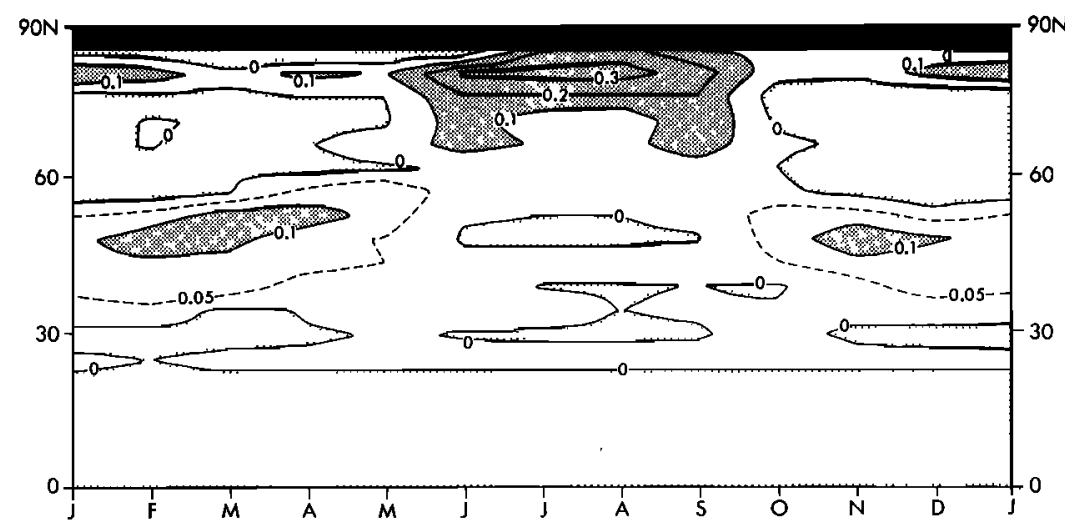

Fig. 15. Latitude-time distribution of the zonally averaged monthly mean difference in surface albedo between the ice sheet and standard experiments for ice-free land points. Only grid points representing ice-free land in both experiments were used to compute the zonal averages. 

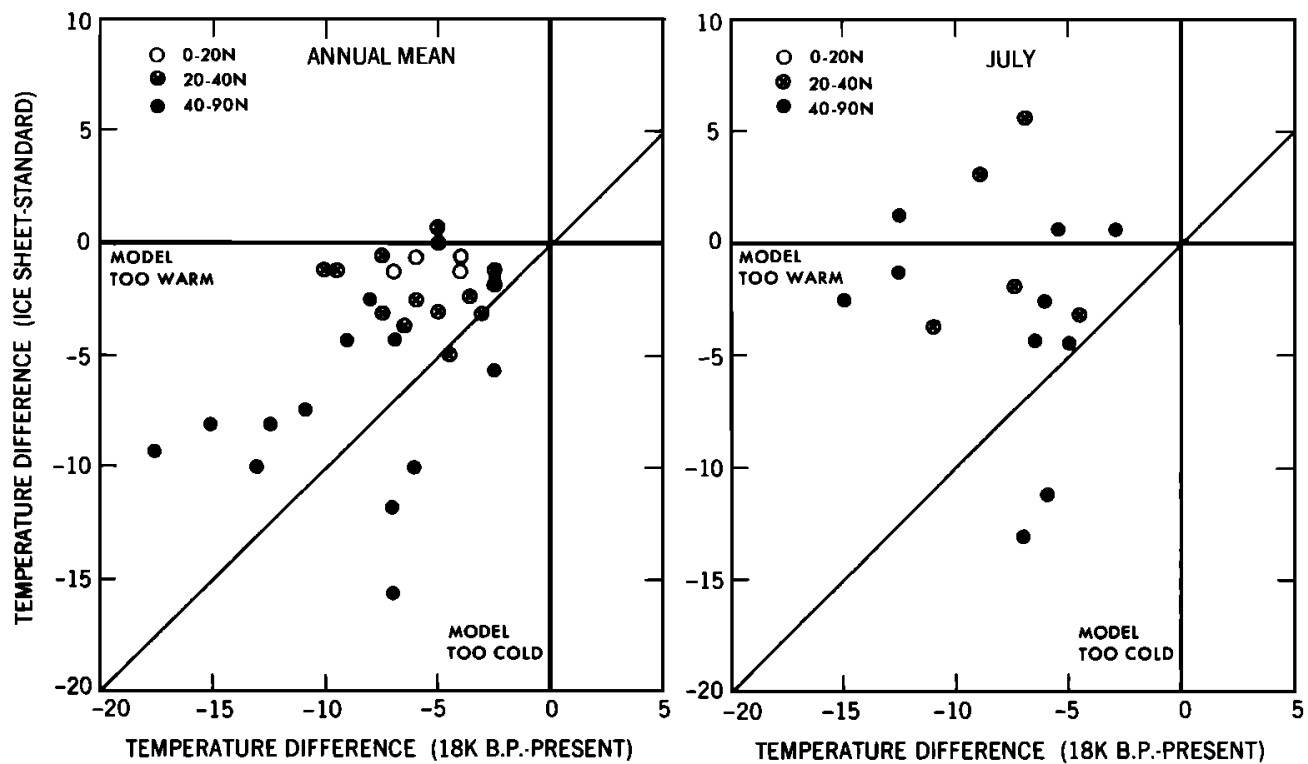

Fig. 16. Comparison of northern hemisphere surface air temperature differences between the ice sheet and standard experiments with temperature differences between 18K B.P. and the present as estimated by Peterson et al. [1979]: (left) annual; (right) July.

of relatively large soil moisture decrease are not statistically significant, particularly those in the tropics and subtropics. Other areas, while statistically significant, are very much regional in scale, representing a small number of model grid points. In contrast to these areas is a large region of soil moisture decrease extending from eastern Europe across much of north central Asia and lying just south of the Eurasian ice sheet. A much less extensive area of smaller soil moisture reduction adjoins the southern margin of the North American ice sheet in a similar manner. The proximity of these regions to major ice sheets makes them interesting places to examine the effects of continental ice sheets on the hydrologic budget.

These areas are also interesting because of geological evidence which may suggest drier climates in these regions during glacial times. Figure 24 shows the global distribution of loess, which is a deposit of unstratified grains of silt. From this figure one can notice the existence of sizable loess deposits in and near the regions of lower soil moisture from the ice sheet experiment. The mechanisms of loess formation and deposition are as follows. Fine particles (predominantly quartz) are produced by the grinding action of glaciers and transported as the glacial ice flows. As melting occurs at the glacial margin, these fine particles are among the outwash material. This outwash material is then deposited along the floodplains of glacial rivers and streams, allowing the silt-sized particles to be transported and deposited by the wind [Smalley, 1972; Kukla, 1975].

Inferences of past climates from modern loess deposits assume that a dry (or at least seasonally dry) climate is necessary for the transportation and deposition of loess material by the wind. If the glacial origin and eolian deposition of loess are accepted, the loess deposits suggest that a climate that was at least seasonally dry occurred near the time of the last glacial maximum. Our current results, which indicate regions of reduced soil moisture to the south of the Eurasian and North American ice sheets, are not inconsistent with these paleoclimatic inferences.

To investigate the mechanisms responsible for these dry zones, soil moisture budgets are computed for the two regions outlined in Figure 23. The region south of the North Ameri- can ice sheet will be called the "Great Plains region," while the region south of the Eurasian ice sheet will be called the "Trans-Urals region." The seasonal variation of monthly mean soil moisture for both the ice sheet and standard experiments along with the difference in monthly mean precipitation and evaporation (including sublimation) between the two experiments are shown for each of these regions in Figure 25. In both regions the reduction of precipitation in the ice sheet experiment is larger than the corresponding reduction in evaporation for nearly all months of the year.

As a consequence an ice-sheet-induced reduction of soil moisture occurs throughout most of the year. An exception occurs in June for the Great Plains region, where little difference in soil moisture exists between the two experiments. For the Trans-Urals region, June is also the time of the smallest soil moisture difference. According to an analysis of the soil moisture budget, this occurs as the spring snowmelt common to both the ice sheet and standard experiments replenishes the soil moisture and reduces the difference between the two experiments. During summer, the soil in the ice sheet experiment is drier than the soil in the standard experiment because the ice-sheet-induced reduction of precipitation is greater than that of evaporation. The differences in soil moisture over both the Great Plains and Trans-Urals regions are maintained throughout autumn and winter seasons when the moisture storage in snow-covered soil hardly changes with time.

To explore the mechanisms responsible for inducing the summer dryness over these two regions in the ice sheet experiment, Figure 26 illustrates the geographical distributions of the differences in the rates of both precipitation and evaporation (including sublimation) during summer between the two experiments. According to this figure, the rate of precipitation in the ice sheet experiment is less than the rate in the standard experiment in both the Great Plains and Trans-Urals regions. These reductions in precipitation rate are much larger than the area mean reduction of $0.035 \mathrm{~cm} \mathrm{~d}^{-1}$ over the Northern Hemisphere continents. While a reduction in evaporation rate also occurs in both regions, it is not as large as the decrease in precipitation rate.

In contrast, Figure 26 indicates a major decrease in evapo- 

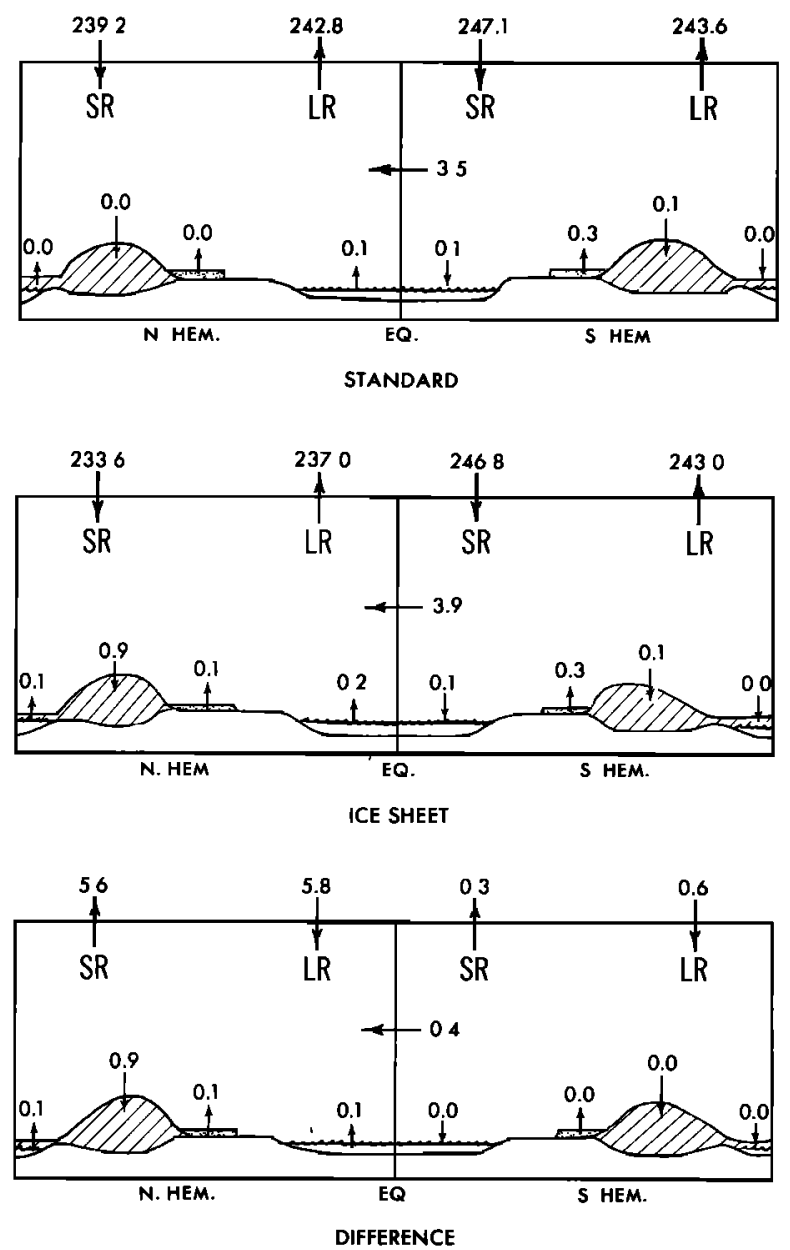

Fig. 17. Box diagrams representing the hemispheric mean energy fluxes (annually averaged) in the atmosphere-ocean-cryosphere system of the model. The arrows at the top of the boxes represent the fluxes of solar (SR) and terrestrial (LR) radiation, and the arrows between the boxes represent the cross-equatorial heat transport. The surface fluxes shown near the bottom of each box represent the heat energy exchanged between the atmosphere and the ocean and cryosphere. The fluxes indicated represent, from left to right in the northern hemisphere box, the heat involved in the growth and decay of sea ice, land ice, and permanent snow cover and the long-term changes in heat storage in the oceanic mixed layer: (top) standard experiment; (center) ice sheet experiment; (bottom) difference between ice sheet and standard experiments.

ration and sublimation over both the North American and Eurasian ice sheets, particularly at their southern margins. This constitutes a reduction in the source of moisture to the atmosphere relative to the standard experiment, where warmer soil is a more abundant moisture source than the cold ice sheets. In fact at locations along the southern flank of the ice sheets a downward flux of water vapor occurs in the summer season as condensation takes place on the ice surface. This was discussed earlier with regard to the heat and ice budgets of the ice sheets. From this evidence we hypothesize that the small amount of moisture supplied to the atmosphere from the cold North American and Eurasian ice sheets is an important factor in the increased aridity of the Great Plains and Trans-Urals regions. These ice sheets are, in effect, moisture sinks which draw atmospheric water vapor away from surrounding regions and reduce its availability for precipitation particularly during the summer season. The Great Plains and Trans-Urals regions are sensitive to this effect, since they are (1) adjacent to the southern margin of the ice

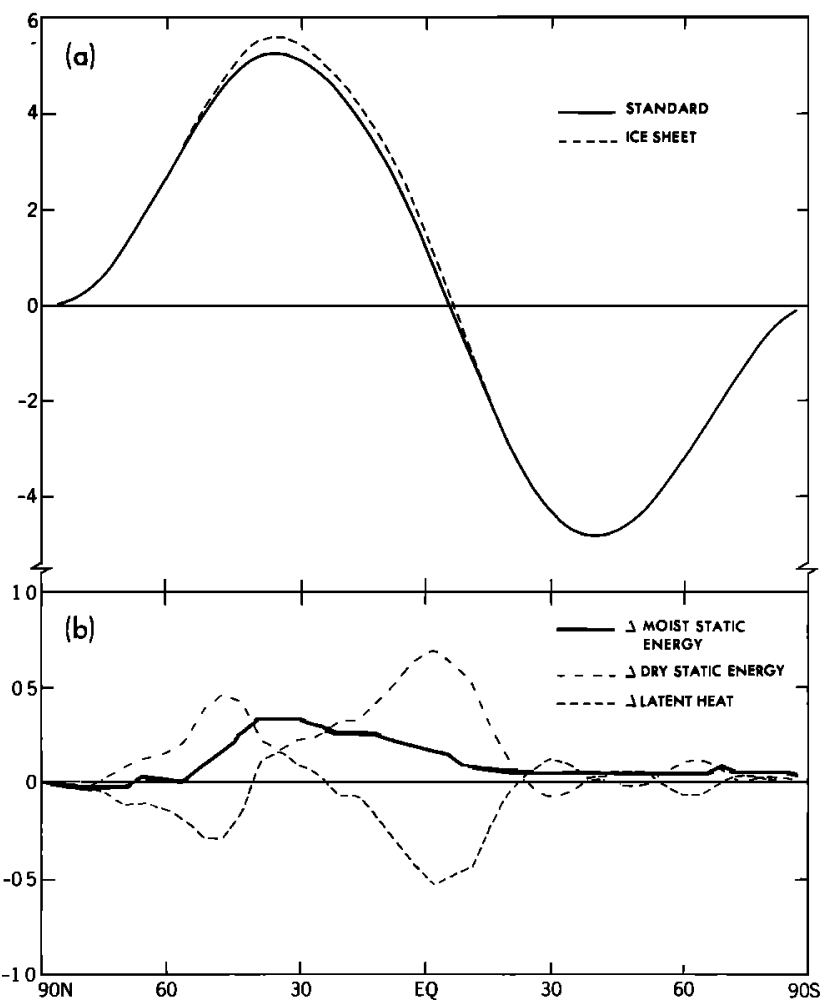

Fig. 18. Latitudinal distributions of (a) annual mean northward transport of moist static energy across a latitude circle obtained from the standard experiment, $(b)$ the differences in the annual mean transports of moist static, dry static, and latent energy between the two experiments (i.e., the ice sheet minus standard experiments). Units are in $10^{15} \mathrm{~W}$.

sheets where the reduction in evaporation is very large and (2) relatively isolated from oceanic moisture sources and regions of oceanic cyclogenesis.

Another factor contributing to the dryness of the TransUrals region also occurs primarily in summer. As pointed out earlier, it is during the summer season that the reduction in precipitation is largest and the large reduction in soil moisture begins to develop (see Figure 25). Thus, although a year-round decrease in precipitation occurs, the summer reduction is quite important. Figure 27 shows the geographical distribution of precipitation in the vicinity of the Eurasian ice sheet for both the ice sheet and standard experiments. Quite prominent in both experiments is a precipitation belt located in the subarctic between $60^{\circ}$ and $75^{\circ} \mathrm{N}$. A pronounced northward shift in the location of this precipitation maximum is observed in the ice sheet experiment. In comparing the position of the precipitation belt to the location of the Eurasian ice sheet, it is evident that its position in the ice sheet experiment corresponds closely to the southern ice margin. This suggests that the shift may be due to enhanced baroclinicity resulting from

TABLE 2. Annual Mean Area-Averaged Ice Budget Components $\left(\mathrm{cm} \mathrm{d}^{-1}\right)$ for the North American and Eurasian Ice Sheets From the Ice Sheet Experiment

\begin{tabular}{lcr}
\hline & North American & Eurasian \\
\hline Snowfall & 0.158 & 0.138 \\
Sublimation & 0.068 & 0.061 \\
Surface melt & 0.302 & 0.365 \\
Net & -0.211 & -0.288 \\
\hline
\end{tabular}




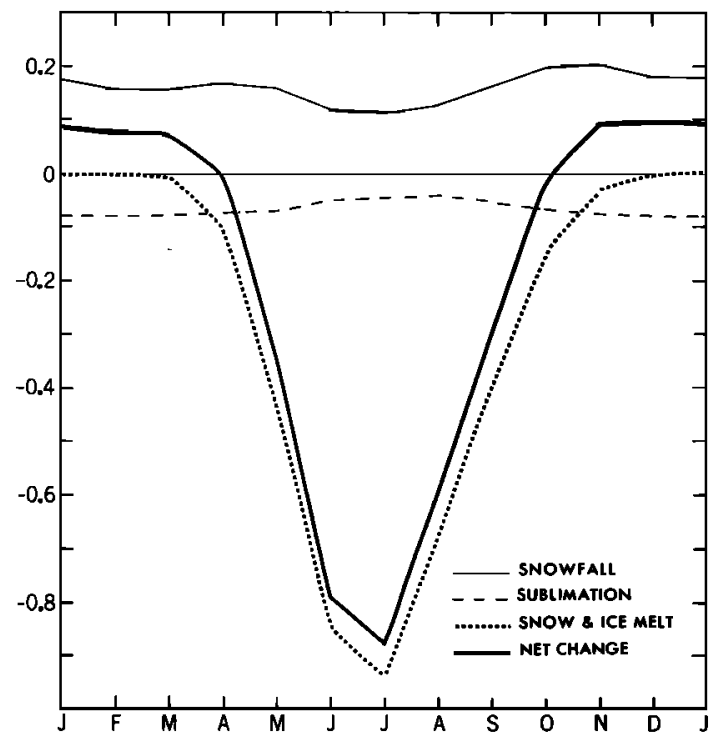

Fig. 19. Seasonal variation of area-averaged ice budget components for the North American ice sheet $\left(\mathrm{cm} \mathrm{d}^{-1}\right)$.

the large contrast in surface temperature across the ice sheet edge. The existence of a mid-tropospheric jet stream which shifts northward to a location very near the ice edge is consistent with this hypothesis.

Snowfall. Since snowfall is one of the key components of the mass budget of an ice sheet, the influence of continental ice sheets on the distribution of snowfall will be briefly discussed. Figure 28 contains the annual mean snowfall rate for the ice sheet experiment. Particularly intense snowfall is present in a belt extending from the southeastern portion of the North American ice sheet to the southwestern portion of the Euras- ian ice sheet at $45^{\circ}-50^{\circ} \mathrm{N}$. This is in marked contrast with the snowfall distribution from the standard experiment (not shown), which features a less intense belt of maximum snowfall at $60^{\circ} \mathrm{N}$, with isolated areas of heavier snowfall in elevated regions such as the Tibetan Plateau. One of the factors responsible for the intense snowfall in the ice sheet experiment is indicated in Figure 29, which illustrates the difference in precipitation rate between the ice sheet and standard experiments. According to this figure, the precipitation rate increases markedly near the southern boundary of the North American ice sheet and is responsible for the heavy snowfall described above. This increase occurs despite an overall ice-sheetinduced reduction of $18 \%$ in the area mean rate of precipitation over the northern hemisphere.

As discussed previously, an intense jet stream in the middle and upper troposphere prevails along the southern boundary of the North American ice sheet in the ice sheet experiment during winter. Associated with the jet is a cyclone track which extends across the North Atlantic from the east coast of North America just south of the ice sheet to the western margin of the Eurasian ice sheet. Cyclones developing in the western portion of this storm track induce heavy precipitation near the southeastern portion of the North American ice sheet. This mechanism is responsible for the increase in precipitation rate in this region. Since the surface air temperature in the vicinity of the ice sheet is below freezing, a major fraction of this precipitation falls as snow.

One can identify another factor responsible for the intense snowfall over the southern margins of the two major ice sheets. It is the ice-sheet-induced increase in the fraction of precipitation which falls as snow. Figure 30 contains the geographical distributions of the snow fraction from the ice sheet and standard experiments and the difference in snowfall fraction between the two experiments. According to this figure, a
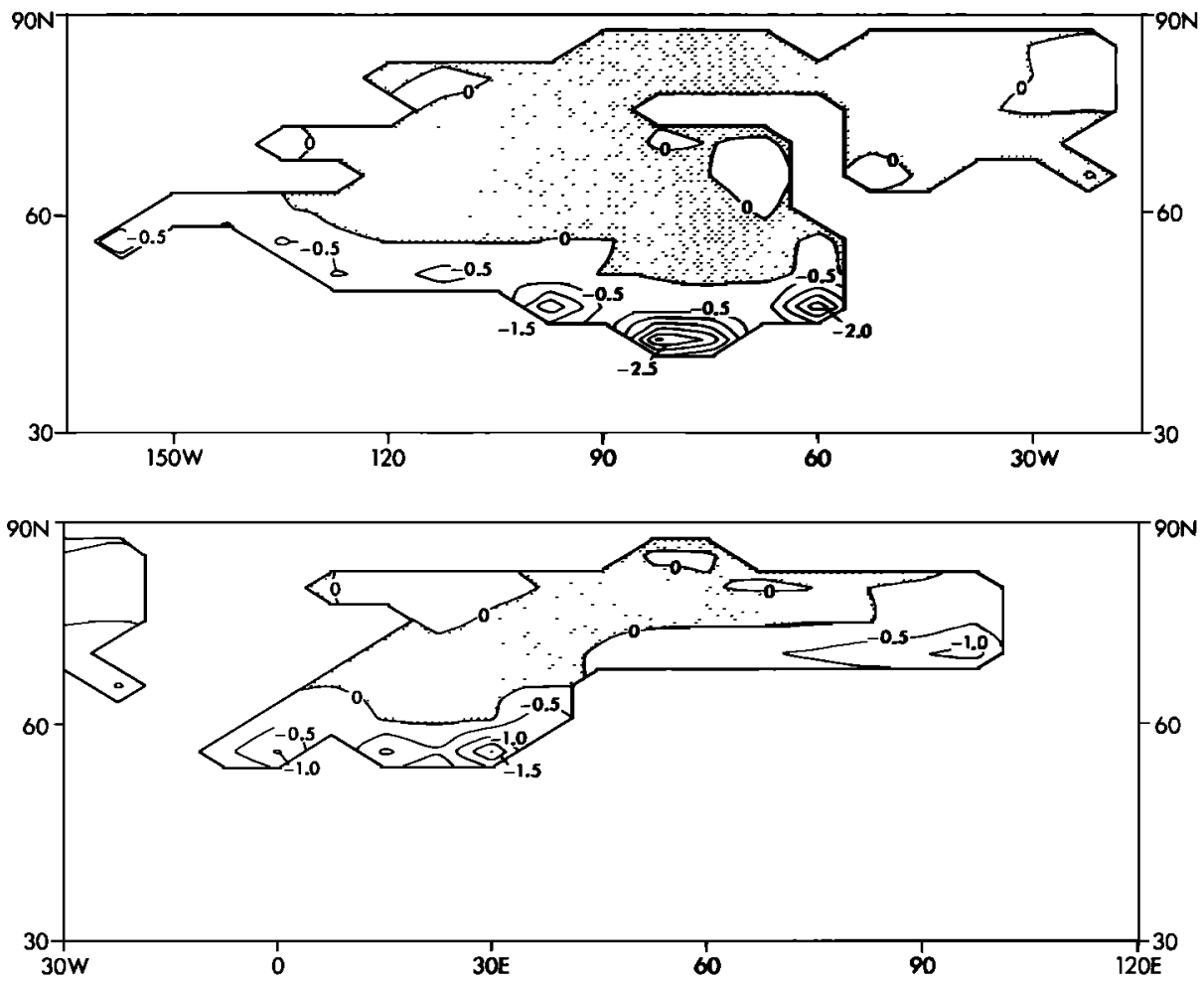

Fig. 20. Geographical distribution of the annually averaged net ice accretion rate $\left(\mathrm{cm} \mathrm{d}^{-1}\right)$. Regions of net ice accretion are shaded: (top) North American ice sheet; (bottom) Eurasian ice sheet. Note that the signs of the components have been changed to represent their contribution to the ice budget. 


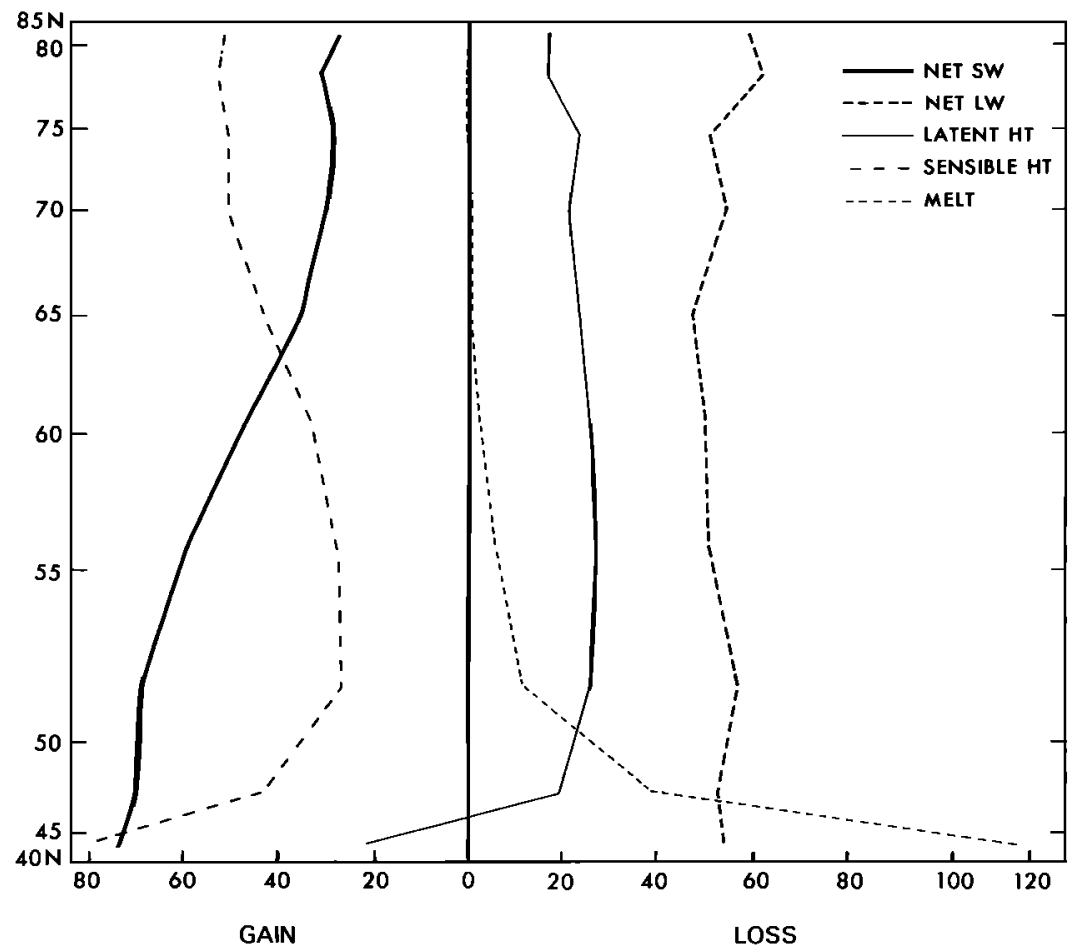

Fig. 21. Latitudinal distribution of annually averaged zonal mean surface heat budget components for the North American ice sheet $\left(\mathrm{W} \mathrm{m}^{-2}\right)$. The latitude scale is adjusted to reflect the ice sheet area in each latitude belt.

large increase in snow fraction occurs over an area extending from the North American ice sheet across the North Atlantic to western Europe and the Eurasian ice sheet. This increase in the snow fraction is due to the reduction in air temperature, particularly in winter, that occurs in the vicinity of the two major ice sheets.

Thus the region of intense snowfall extending from the southeastern portion of the North American ice sheet to the southwestern portion of the Eurasian ice sheet is due not only to the increased snow fraction in the ice sheet experiment but also to the increased precipitation brought about by a cyclone track which forms along the ice sheet margin. This mechanism for the enhancement of snowfall along the equatorward boundary of a major ice sheet may play an important role in the southward extension of an ice sheet during its growth phase. The formation of a cyclone track (and its associated precipitation belt) due to enhanced baroclinicity at the equatorward margin of an ice sheet may be an important positive feedback mechanism in the growth of continental ice sheets. While this experiment provides some circumstantial evidence for this mechanism, a different set of numerical experiments would be necessary to evaluate it properly.

\section{Concluding Remarks}

The present study attempts to determine the influence of the massive $18 \mathrm{~K}$ B.P. ice sheets upon climate. It is shown that in

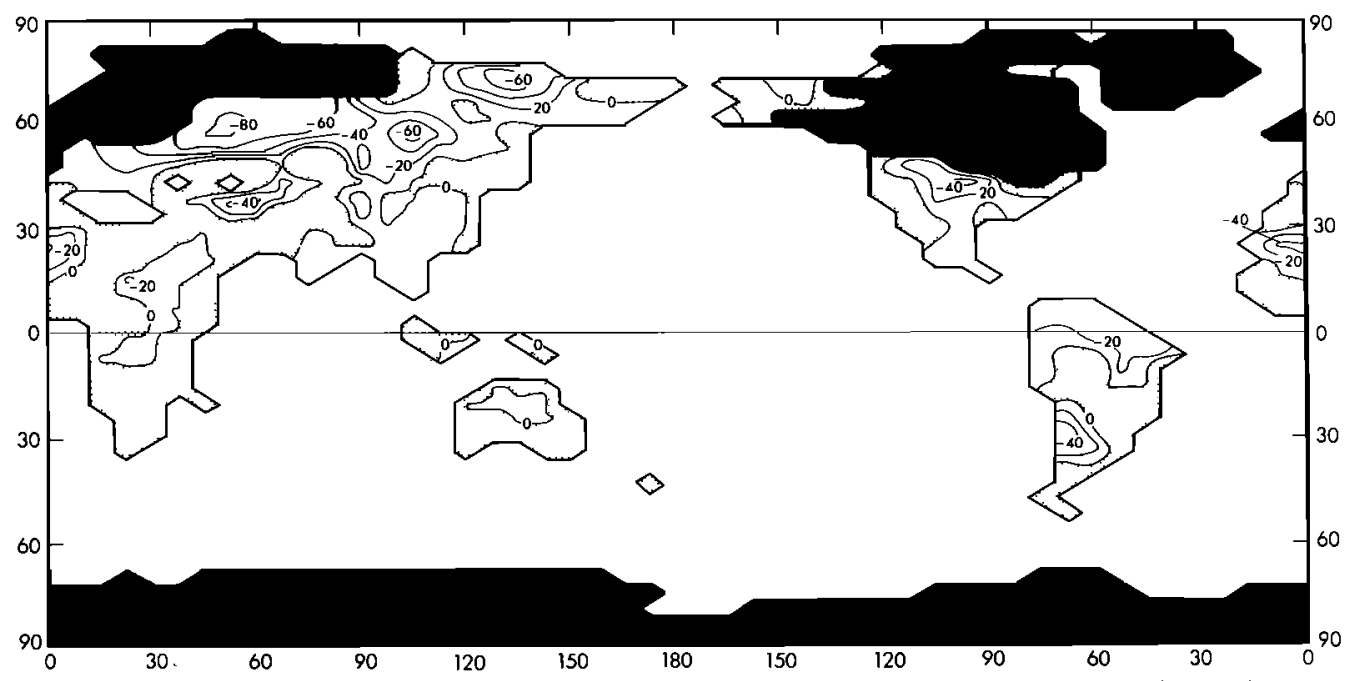

Fig. 22. Percentage change in annual mean soil moisture from the standard to the ice sheet experiment. Areas covered by continental ice are blacked out; stippling indicates areas with an increase of soil moisture. (Since the statistical significance of the change in soil moisture is small in regions of increase of soil moisture, no contours are drawn in these regions to improve the clarity of the illustration). 


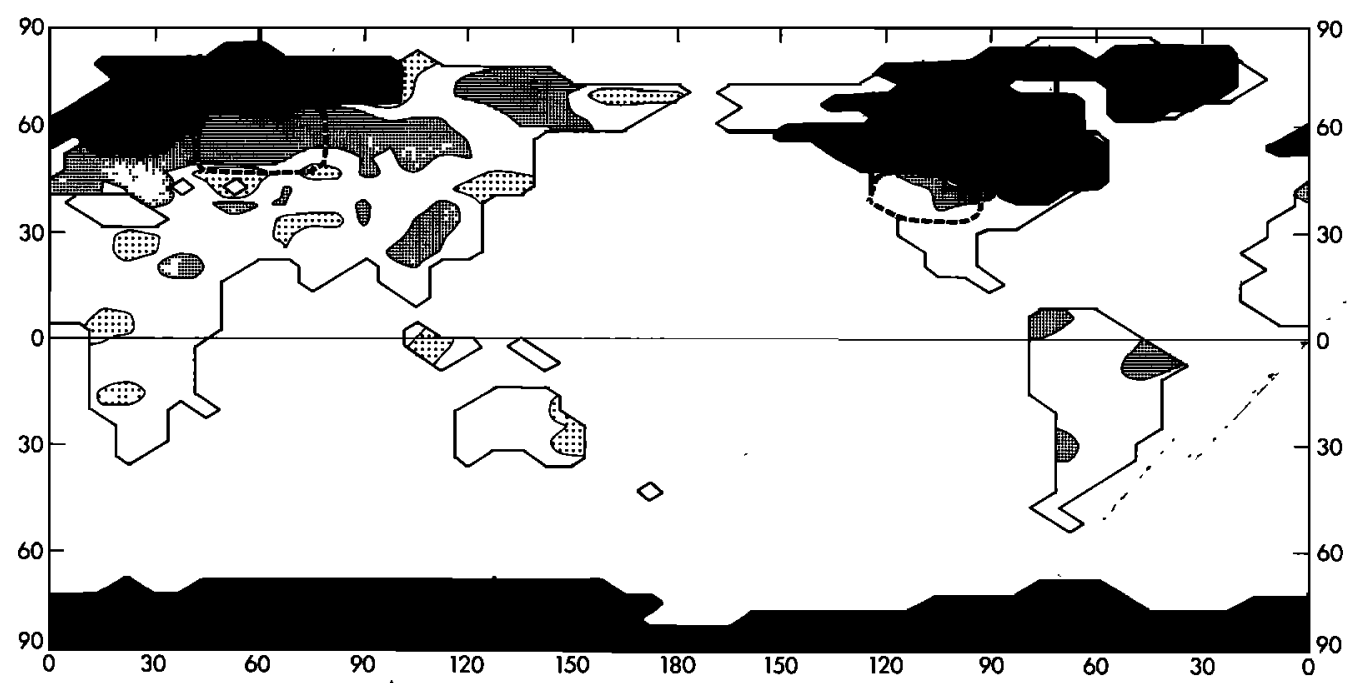

Fig. 23. Geographical distribution of statistically significant changes in soil moisture. Dense and light stippling indicate areas of soil moisture increase and decrease, respectively, that are significant at the $95 \%$ level. Areas covered by continental ice are blacked out. The dashed outlines denote areas referred to in the text.

the northern hemisphere the North American ice sheet exerts a profound influence upon the tropospheric flow field in winter and produces a split flow which straddles the ice sheet. In the lower troposphere the northern branch of the flow passes along the northern periphery of the ice sheet, where a cold air mass develops due to the intense reflection of insolation. This cold air flows over the North Atlantic Ocean and contributes to the maintenance of thick sea ice there. Because of this intense outflow of cold air, the continental ice sheets exert a stronger influence upon the surface air temperature and SST of the North-Atlantic Ocean than the corresponding temperatures of the North Pacific Ocean. The distribution of the ice-sheet-induced change in northern hemisphere SST as determined by the present numerical experiments resembles the distribution of the difference between the present and $18 \mathrm{~K}$ B.P. SST estimated by CLIMAP.

A large reduction of surface air temperature in the ice sheet experiment is noted in the northern hemisphere in winter. The largest reductions occur over the continents and oceanic regions covered by sea ice. During summer, only a small reduction in temperature occurs over the continents. The snow- albedo feedback process is found to be partly responsible for this seasonal variation as extensive snow cover forms well south of the ice sheets during winter but little snow falls in summer. A comparison of computed differences in surface air temperature between the two experiments and temperature difference between 18K B.P. and the present as estimated by geological and biological evidence also suggests that the icesheet-induced summer cooling as modeled is smaller than that at $18 \mathrm{~K}$ B.P.

Analysis of the ice budgets of the North American and Eurasian ice sheets indicate a net depletion of ice for both ice sheets. Surface melt during summer along the southern margins of the ice sheets is instrumental in producing this net depletion. The small reduction of surface air temperature over the continents in summer may be an important factor in this process.

Hydrologic changes in the model climate are also found. The most noteworthy of these changes are the statistically significant decreases in soil moisture found to exist in a zone located to the south of the North American and Eurasian ice sheets. These findings are consistent with some geological evi-

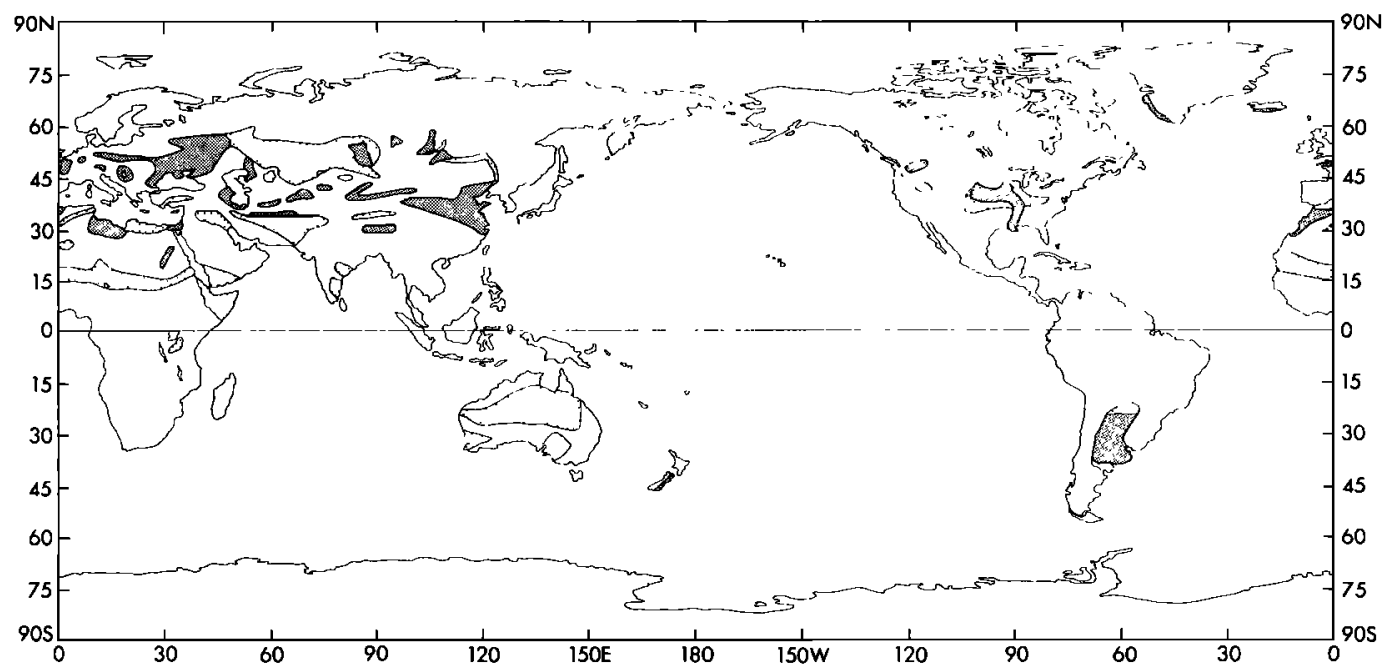

Fig. 24. Global distribution of loess deposits. Dense stippling indicates proven loess deposits, while light stippling indicates deposits that are possibly loess (redrawn from Scheidig [1934]). 


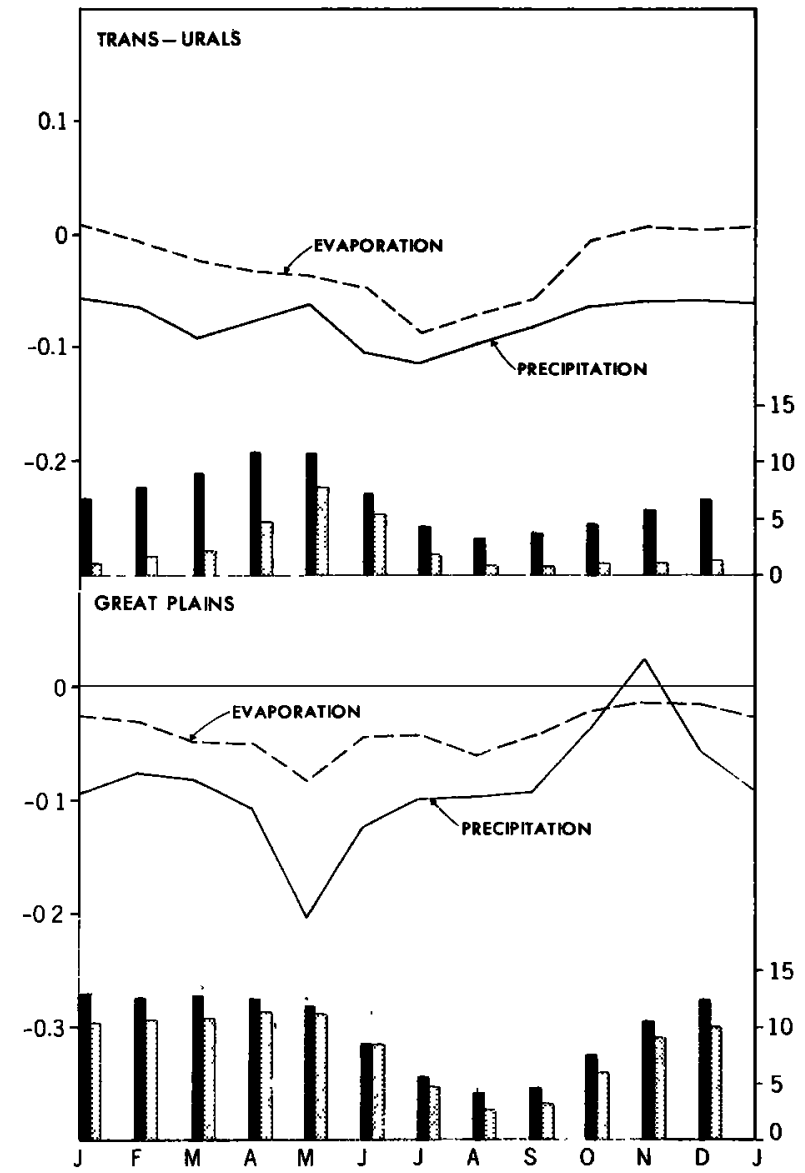

Fig. 25. Seasonal variation in soil moisture $(\mathrm{cm})$ for the ice sheet and standard experiments. The vertical bars indicate the monthly mean soil moisture, with the solid and stippled bars representing the standard and ice sheet experiments, respectively. Differences in precipitation and evaporation (including sublimation) between the two experiments $\left(\mathrm{cm} \mathrm{d}^{-1}\right)$ are shown by the solid and dashed lines, respectively: (top) Trans-Urals region; (bottom) Great Plains region.

dence of drier climates during the last glacial maximum. The reduction of soil moisture in these regions results primarily from a year-round decrease in precipitation. This decrease can be related to a reduction in the amount of moisture supplied to the atmosphere by evaporation and sublimation from the nearby ice sheets. In addition an ice-sheet-induced shift of a summer precipitation belt contributes to the reduction in precipitation south of the Eurasian ice sheet.
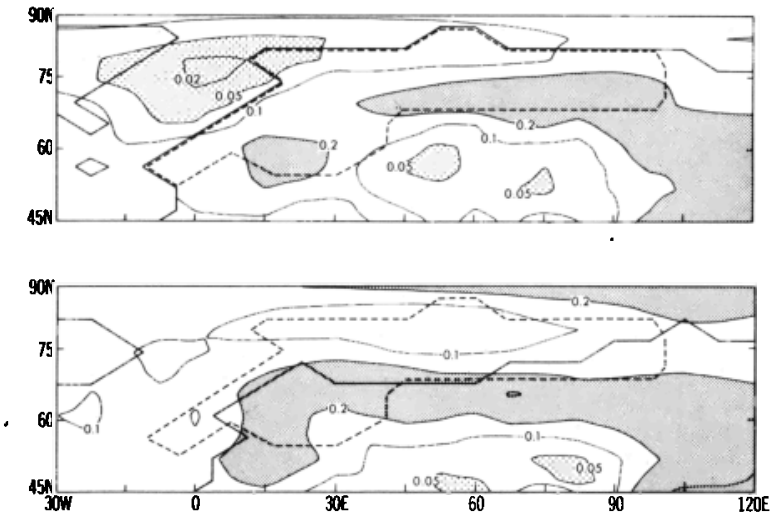

Fig. 27. Summer (JJA) distribution of precipitation for Eurasia and vicinity ( $\mathrm{cm} \mathrm{d} \mathrm{d}^{-1}$ ): (top) ice sheet experiment; (bottom) standard experiment. For reference, the outer boundary of the 18K B.P. Eurasian ice sheet is indicated by dashed lines in the maps from both experiments.

Despite these substantial changes in the northern hemisphere climate it is noted that the $18 \mathrm{~K}$ B.P. ice sheets have very little influence on atmospheric temperature and SST in the southern hemisphere. This is because the loss of heat energy due to the reflection of solar radiation by the continental ice sheets in the northern hemisphere is almost completely compensated by the in situ reduction of the upward terrestrial radiation at the top of the atmosphere. Thus the heat exchange between the two hemispheres hardly changes despite the reduction of atmospheric temperature in the northern hemisphere. In other words the in situ radiative damping in the northern hemisphere is much more effective than the diffusive damping through interhemispheric heat exchange.

These results fail to explain why the southern hemisphere SST's during the last glacial maximum were as cold as indicated by the reconstructions of CLIMAP [CLIMAP Project, 1981]. One mechanism which would transmit a northern hemisphere response to the southern hemisphere is a change in the rate of heat exchange between the two hemispheres. For example if the intensity of the interhemispheric ocean circulation changes between glacial and interglacial periods [e.g., Rooth, 1982], it is expected that the interhemispheric heat exchange by ocean currents also changes, resulting in a southern hemisphere temperature change. In order to evaluate the influence of oceanic heat transport on the sensitivity of the southern hemisphere climate it is desirable to repeat the pres-
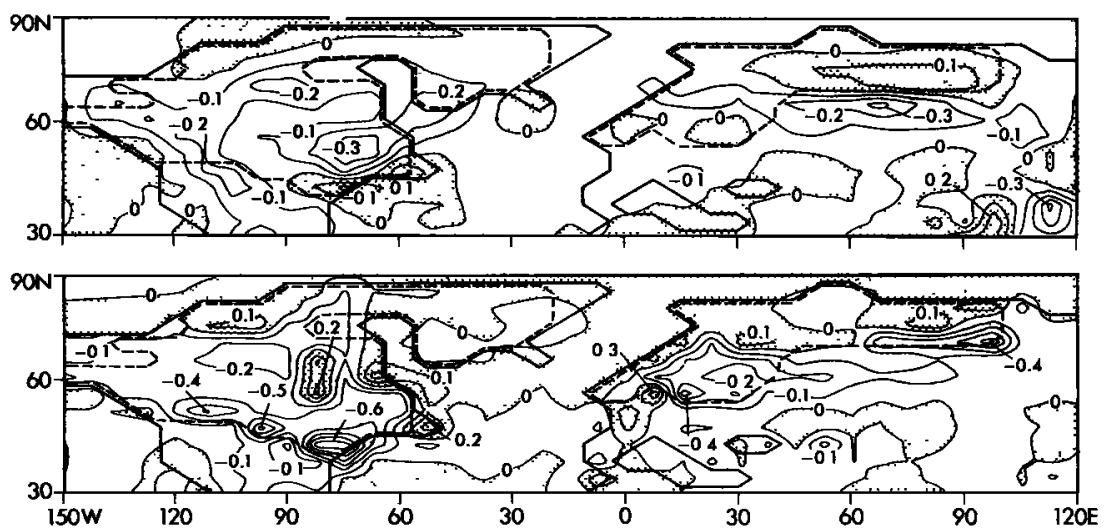

Fig. 26. Geographical distributions of the differences in precipitation (top) and evaporation including sublimation (bottom) between the ice sheet and standard experiments for the summer (JJA) season. The dashed lines indicate the boundaries of the 18K B.P. continental ice sheets. Units are $\mathrm{cm} \mathrm{d}^{-1}$. 


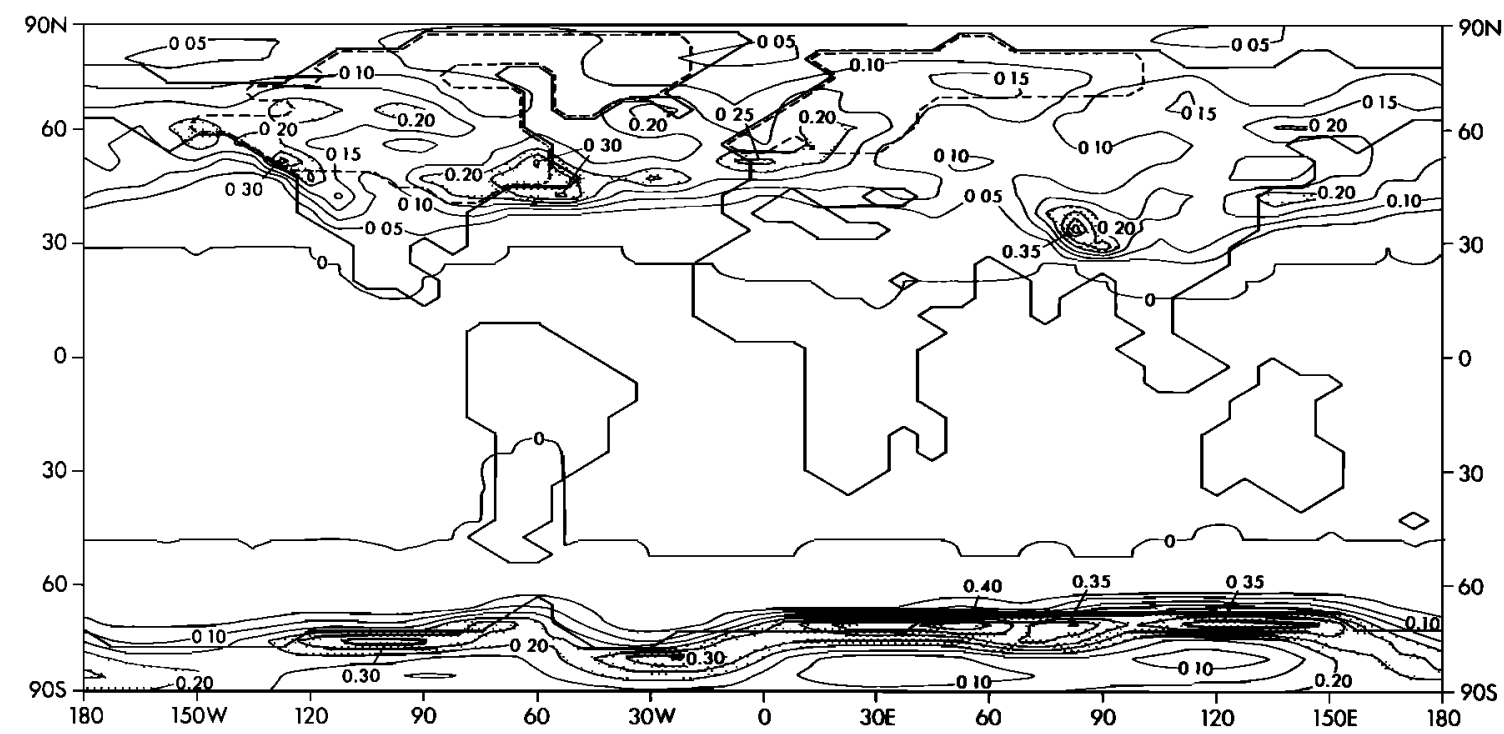

Fig. 28. Geographical distribution of annual mean snowfall $\left(\mathrm{cm} \mathrm{d} \mathrm{d}^{-1}\right.$ of water equivalent) from the ice sheet experiment. The dashed lines indicate the boundaries of the continental ice sheets.

ent study by use of a coupled ocean-atmosphere model which incorporates the effects of ocean currents. Unfortunately, currently available models of the coupled ocean-atmosphere system [e.g., Manabe et al., 1979a] do not satisfactorily simulate the global distribution of water masses and oceanic heat transport. It appears that further improvement of coupled models is required before this issue can be reliably assessed.

Changes in the atmospheric carbon dioxide concentration could also produce the almost simultaneous change of temperature in both hemispheres. The recent analysis of ice cores from Greenland and Antarctica indicates significantly lower $\mathrm{CO}_{2}$ concentrations during the $18 \mathrm{~K}$ B.P. ice age [Neftel et al., 1982]. Such reductions could account for a large portion of the southern hemisphere temperature changes indicated in the CLIMAP results. The impact of the reduction in atmospheric $\mathrm{CO}_{2}$ upon the climate of an ice age will be the subject of future numerical experiments.

As pointed out by Held [1982], the results discussed here have important implications for the astronomical theory of the ice ages. Spectral analysis of deep sea cores [e.g., Hays et al., 1976] suggests that the temporal variation of the orbital parameters of the earth are responsible for the large climate fluctuations during the Quaternary. However, the results of numerical experiments with simple energy balance models of climate indicate that the variation of orbital parameters affects the climate of the northern hemisphere but has relatively little impact upon that of the southern hemisphere [e.g., Suarez and Held, 1979]. Although the temporal fluctuations of the orbital parameters significantly influence the seasonal variation of insolation, they hardly affect its annual mean. Since the thermal inertia of the ocean tends to smooth out the climatic response to the seasonal variation of insolation, it is expected that the variations in orbital parameters has a relatively small effect on the temperature of the predominantly oceanic southern hemisphere. Thus in order to satisfactorily explain the fluctuations of the Quarternary climate it appears necessary to consider other factors, such as oceanic heat transport and atmospheric $\mathrm{CO}_{2}$ concentration.

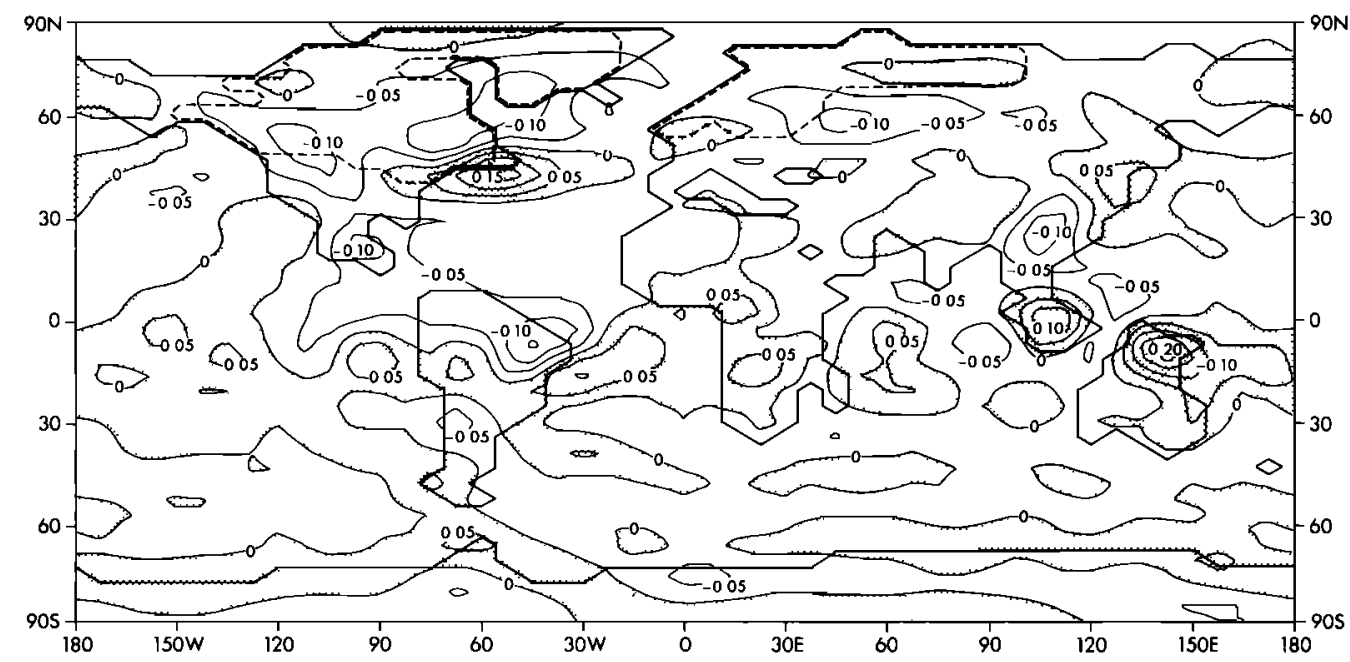

Fig. 29. Geographical distribution of the difference in precipitation (annually averaged) between the ice sheet and standard experiments $\left(\mathrm{cm} \mathrm{d}^{-1}\right.$ ). The grid point data have been smoothed with a two-dimensional 1-2-1 filter to eliminate small-scale variations. The dashed lines indicate the boundaries of the 18K B.P. continental ice sheets. 

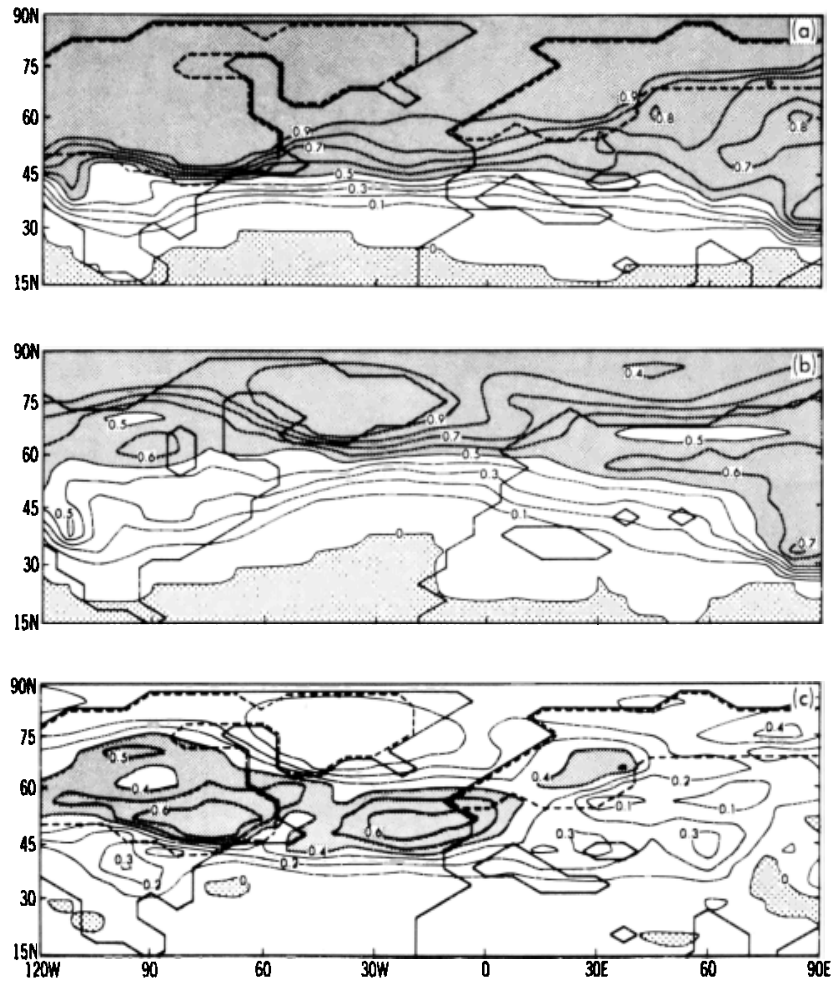

Fig. 30. Geographical distribution of (a) annual mean snow fraction (i.e., the fraction of precipitation falling as snow) obtained from the ice sheet experiment, (b) annuai mean snow fraction obtained from the standard experiment, and (c) the difference between the two fractions (i.e., the ice sheet minus standard experiments). The dashed lines indicate the boundaries of the continental ice sheets.

Acknowledgments. D. Hahn played an important role in the design of this experiment and supervised its execution. D. Daniel managed the time integration of the numerical model carefully and efficiently. R. Stouffer and W. Prettyman contributed to the development of versatile graphics programs used in analysis of model results and preparation of illustrations. I. Held, J. Kutzbach, J. D. Mahlman, S. L. Thompson, and K. Bowman reviewed this work thoroughly and made many constructive comments. G. Kukla was particularly helpful in interpreting the paleoclimatic implications of loess. J. Kennedy typed the manuscript cheerfully and swiftly through many revisions, and J. Conner, P. Tunison, W. Ellis, M. Zadworney, C. Raphael, and J. Varanyak prepared the final versions of the illustrations.

\section{REFERENCES}

Bourke, W., A multi-level model, 1, Formulation and hemispheric integrations, Mon. Weather Rev., 102, 687-701, 1974.

Bryan, K., Climate and the ocean circulation, 3, The ocean model, Mon. Weather Rev., 97, 806-827, 1969.

CLIMAP Project, The surface of the ice-age earth, Science, 191, 11311136, 1976.

CLIMAP Project, Seasonal reconstructions of the earth's surface at the last glacial maximum, Geol. Soc. Am. Map Chart Ser., MC-36, 1981.

Crutcher, H. L., and J. M. Meserve, Selected level heights, temperature, and dew points for the Northern Hemisphere, Rep. NAVAIR 50-IC-52, U.S. Nav. Weather Serv., Washington, D. C., 1970.

Gates, W. L., Modeling the ice age climate, Science, 19I, 1138-1144, $1976 a$.

Gates, W. L., The numerical simulation of ice-age climate with a global general circulation model, J. Atmos. Sci., 33, 1844-1873, $1976 b$.

Gordon, C. T., and W. F. Stern, The GARP programme on numerical experimentation, Rep. 7, World Meteorol. Org., Geneva, 1974.

Gordon, C. T., and W. F. Stern, A description of the GFDL global spectral model, Mon. Weather Rev., 110, 625-644, 1982.
Hays, J. D., J. Imbrie, and N. J. Shackleton, Variations in the earth's orbit: Pacemaker of the ice ages, Science, 194, 1121-1132, 1976.

Heath, G. R., Simulations of a glacial paleoclimate by three different atmospheric general circulation models, Paleogeogr., Paleoclimatol., Paleoecol., 26, 291-303, 1979.

Held, I. M., Climate models and the astronomical theory of the ice ages, Icarus, 50, 449-461, 1982.

Hoskins, B. J., and A. J. Simmons, A multi-layer spectral model and the semi-implicit method, Quat. J. R. Meteorol. Soc., 104, 91-102, 1975.

Hughes, T. J., G. H. Denton, B. G. Andersen, D. H. Schilling, J. L. Fastook, and C. S. Lingle, The last great ice sheets: A global view, in The Last Great Ice Sheets, edited by G. H. Denton and T. J. Hughes, John Wiley, New York, 1981.

Kukla, G., Loess stratigraphy of Central Europe, in After the Australopithecines, edited by K. W. Butzer and G. L. Isaac, Mouton Publishers, The Hague, 1975.

Lacis, A. A., and J. E. Hansen, A parameterization for the absorption of solar radiation in the earth's atmosphere, J. Atmos. Sci., 31, 118-133, 1974.

Manabe, S., Climate and ocean circulation, 1, The atmospheric circulation and the hydrology of the earth's surface, Mon. Weather Rev., 97, 739-774, 1969.

Manabe, S., and A. J. Broccoli, Influence of the CLIMAP ice sheet on the climate of a general circulation model: Implications for the Milankovitch theory, in Milankovitch and Climate, edited by $\mathbf{A}$. Berger, J. Imbrie, J. Hays, G. Kukla, and B. Saltzman, D. Reidel, Hingham, Mass., 1984a.

Manabe, S., and A. J. Broccoli, Ice age climate and continental ice sheets: Some experiments with a general circulation model, Annal. Glaciol., 5, 100-105, $1984 b$.

Manabe, S., and D. G. Hahn, Simulation of the tropical climate of an ice age, J. Geophys. Res., 82, 3889-3911, 1977.

Manabe, S., and D. G. Hahn, Simulation of atmospheric variability, Mún. Weather Revi., 109, 2260-2286, 1981.

Manabe, S., and R. J. Stouffer, Sensitivity of a global climate model to an increase of $\mathrm{CO}_{2}$ concentration in the atmosphere, $J$. Geophys. Res., 85, 5529-5554, 1980.

Manabe, S., J. Smagorinsky, and R. F. Strickler, Simulated climatology of a general circulation model with a hydrologic cycle, Mon. Weather Rev., 93, 769-798, 1965.

Manabe, S., K. Bryan, and M. J. Spelman, A global oceanatmosphere climate model with seasonal variation for future studies of climate sensitivity, Dyn. Atmos. Oceans, 3, 393-426, 1979a.

Manabe, S., D. G. Hahn, and J. L. Holloway, Climate simulation with GFDL spectral models of the atmosphere, GARP Publ. Ser. 22, World Meteorol. Org., Geneva, $1979 b$.

Milankovitch, M., K. Serb. Akad. Beogr. Spec. Publ. 132, translated from German by the Israel Program for Scientific Translations, Jerusalem, 1969.

Neftel, A., H. Oeschger, J. Schwander, B. Stauffer, and R. Zumbrunn, Ice core sample measurements give atmospheric $\mathrm{CO}_{2}$ content during the past 40,000 yr., Nature, 295, 220-222, 1982.

Orszag, S. A., Transform method for calculation of vector-coupled sums: Application to the spectral form of the vorticity equation, $J$. Atmos. Sci., 27, 890-895, 1970.

Panofsky, G. M., and G. W. Brier, Some Applications of Statistics to Meteorology, The Pennsylvania State University, University Park, 1958.

Peterson, G. M., T. Webb III, J. E. Kutzbach, T. van der Hammen, T. A. Wijmstra, and F. A. Street, The continental record of environmental conditions at 18,000 yr B.P.: An initial evaluation, Quat. Res., 12, 47-82, 1979.

Posey, J. W., and P. F. Clapp, Global distribution of normal surface albedo, Geofis. Int., 4, 33-48, 1964.

Robert, A., The integration of a low-order spectral form of the primitive equations, J. Meteorol. Soc. Jpn., 44, 237-244, 1966

Rodgers, C. D., and C. D. Walshaw, The computation of infrared cooling rate in planetary atmospheres, Q. J. Roy. Meteorol. Soc., 92, 67-92, 1966.

Rooth, C., Hydrology and ocean circulation, Progr. Oceanogr., 11, 131-149, 1982.

Scheidig, A., Der Loss, p. 7, Theodor Steinkopff, Dresden, 1934.

Smalley, I. J., The interaction of great rivers and large deposits of primary loess, Trans. N. Y. Acad. Sci. Ser. 2, 34, 534-542, 1972.

Stone, H. M., and S. Manabe, Comparison among various numerical models designed for computing infrared cooling, Mon. Weather Rev., 96, 735-741, 1968 
Suarez, M. J., and I. M. Held, The sensitivity of an energy balance climate model to variations in orbital parameters, J. Geophys. Res., 84, 4825-4836, 1979.

Taljaard, J. J., H. van Loon, H. L. Crutcher, and R. L. Jenne, Climate of the upper air, 1, Southern hemisphere, Rep. NAV AIR 50-IC-55, U.S. Nav. Weather Serv., Washington, D. C., 1969.
A. J. Broccoli and S. Manabe, Geophysical Fluid Dynamics Laboratory/NOAA, Princeton University, Princeton, NJ 08542.

(Received May 22, 1984;

revised September 17, 1984;

accepted September 18, 1984.) 